\title{
Quantifying Nonlinearity Susceptibility via Site-Response Modeling Uncertainty at Three Sites in the Los Angeles Basin
}

\author{
by Dominic Assimaki, Wei Li, Jamison Steidl, and Jan Schmedes
}

\begin{abstract}
The effects of near-surface soil stratigraphy on the amplitude and frequency content of ground motion are accounted for in most modern U.S. seismic design codes for building structures as a function of the soil conditions prevailing in the area of interest. Nonetheless, currently employed site-classification criteria do not adequately describe the nonlinearity susceptibility of soil formations, which prohibits the development of standardized procedures for the computationally efficient integration of nonlinear ground response analyses in broadband ground-motion simulations. In turn, the lack of a unified methodology for nonlinear site-response analyses affects both the prediction accuracy of site-specific ground-motion intensity measures and the evaluation of site-amplification factors when broadband simulations are used for the development of hybrid attenuation relations. In this article, we introduce a set of criteria for quantification of the nonlinearity susceptibility of soil profiles based on the site conditions and incident ground-motion characteristics, and we implement them to identify the least complex ground response prediction methodology required for the simulation of nonlinear site effects at three sites in the Los Angeles basin. The criteria are developed on the basis of a comprehensive nonlinear site-response modeling uncertainty analysis, which includes both detailed soil profile descriptions and statistical adequacy of ground-motion time histories. Approximate and incremental nonlinear models are implemented, and the limited site-response observations are initially compared to the ensemble site-response estimates. A suite of synthetic ground motions for rupture scenarios of weak, medium, and large magnitude events (M 3.5-7.5) is next generated, parametric studies are conducted for each fixed magnitude scenario by varying the source-to-site distance, and the variability introduced in ground-motion predictions is quantified for each nonlinear site-response methodology. A frequency index is developed to describe the frequency content of incident ground motion relative to the resonant frequencies of the soil profile, and this index is used in conjunction with the rock-outcrop acceleration peak amplitude $\left(\mathrm{PGA}_{\mathrm{RO}}\right)$ to identify the site conditions and ground-motion characteristics where incremental nonlinear analyses should be employed in lieu of approximate methodologies. We show that the proposed intensity-frequency representation of ground motion may be implemented to describe the nonlinearity susceptibility of soil formations in broadband simulations by accounting both for the magnitude-distance-orientation characteristics of seismic motion and the profile stiffness characteristics. The synthetic ground-motion predictions are next used for the development of site-amplification factors for the alternative site-response methodologies, and the results are compared to published site factors of attenuation relations. For the site conditions investigated, currently established amplification factors compare well with synthetic simulations for class $C$ and $D$ site conditions, while long-period amplification factors are overestimated by a factor of 1.5 at the class $E$ site, where site-specific nonlinear analyses should be employed for levels of $\mathrm{PGA}_{\mathrm{RO}}>0.2 \mathrm{~g}$.
\end{abstract}




\section{Introduction}

The effects of a soil column upon strong ground motion have been well documented and studied analytically for many years. Multiple published studies (e.g., Wiggins, 1964; Idriss and Seed, 1968; Borcherdt and Gibbs, 1976; Joyner et al., 1976; Berrill, 1977; Duke and Mal, 1978; Chin and Aki, 1991; Darragh and Shakal, 1991; Silva, 1991; Hartzell, 1992; Silva and Stark, 1992; Su et al., 1992) have shown that during small and large earthquakes, the surface soil motion can differ in significant and predictable ways from that on adjacent rock outcrops, and observational and recorded evidence from past catastrophic events has shown that the variability of soil stratigraphy at a given area may significantly affect the variability in seismic intensity and structural damage severity (Rosenblueth, 1960; Ohsaki, 1969; Seed et al., 1972; Tezcan et al., 1979; Seed and Romo, 1987; Housner and Thiel, 1990; Japanese Geotechnical Society, 1996; Earthquake Engineering Research Institute, 2000).

The effects of near-surface soil stratigraphy on the amplitude and frequency content of ground motion are accounted for in most modern U.S. seismic design codes for building structures as a function of the soil conditions prevailing in the area of interest. In particular, in parts 1 and 2 of the Building Seismic Safety Council (BSSC, (2001)), source and path effects are estimated on maps showing the results of probabilistic seismic-hazard analyses (PSHA) for a particular site condition referred to as the reference site. Next, soil profiles are categorized on the basis of the average shear-wave velocity in the upper $30 \mathrm{~m}$ of the site $\left(V_{s 30}\right)$ (Table 1$)$, and site effects are included to improve the accuracy of groundmotion predictions by either adjustment of PHSA predictions via site-amplification factors or by means of site-specific geotechnical analyses of local ground response effects.

When the soil conditions in the area of interest indicate that site-specific analyses need to be conducted (category $E$ and $F$ ), these analyses address either ground response or ground failure problems distinguished on the basis of permanent deformations. Ground response problems involve insignificant residual deformations and may therefore be addressed by means of either approximate or fully nonlinear analyses. Ground failure problems, however, involve substantial permanent ground deformations, which in turn control the performance of structures and facilities of interest and require nonlinear analyses to be conducted (Kramer, 2006).
While, however, nonlinear models are necessary when large strains and permanent displacements are expected, their prediction accuracy depends on the constitutive material law that governs soil behavior. Elaborate constitutive laws require numerous parameters that need to be determined through laboratory and field techniques and are therefore associated with considerable cost and effort in design practice because they require both detailed site characterization and significant engineering time for analysis.

Resolving the physics of nonlinear behavior of sediments to identify the conditions under which nonlinear analyses are necessary and the adequate complexity of the nonlinear model to be employed requires a good estimate of the input motion. To that end, perhaps the most reliable source of information is provided by downhole arrays in seismically active areas (e.g., Borcherdt, 1970; Seed and Idriss, 1970; Hartzell, 1992; Wen et al., 1994; Zeghal and Elgamal, 1994; Elgamal et al., 1995; Iai et al., 1995; Satoh et al., 1995; Sato et al., 1996; Steidl et al., 1996; Aguirre and Irikura, 1997; Boore and Joyner, 1997; Satoh et al., 2001). The use, however, of downhole array data for the establishment of criteria to describe the nonlinearity susceptibility of soil formations subjected to strong ground shaking accompanied by the least complex methodology for implementation involves a twofold impediment: (i) the scarcity of near-surface geotechnical information usually results in predictions of surface ground motion that poorly compare with weak-motion observations, a discrepancy further aggravated for strong ground motion that may be associated with irreversible material deformations and (ii) the paucity of design-level records that does not allow a statistically significant number of strongmotion downhole recordings to be compiled to a mathematically sound investigation of nonlinear site-response predictions via idealized models.

In this article, we develop a set of criteria to quantify the soil nonlinearity susceptibility and identify the least complex ground response prediction methodology that should be employed as a function of the soil properties and the groundmotion characteristics. The criteria are developed on the basis of a comprehensive nonlinear site-response modeling uncertainty analysis at three downhole array sites in the Los Angeles basin, which includes both detailed soil profile descriptions and statistical adequacy of ground-motion time

Table 1

Site Categories in NEHRP Provisions

\begin{tabular}{|c|c|c|}
\hline NEHRP Category & Description & Mean Shear-Wave Velocity to $30 \mathrm{~m}$ \\
\hline A & Hard rock & $>1500 \mathrm{~m} / \mathrm{sec}$ \\
\hline$B$ & Firm to hard rock & $760-1500 \mathrm{~m} / \mathrm{sec}$ \\
\hline$C$ & Dense soil, soft rock & $360-760 \mathrm{~m} / \mathrm{sec}$ \\
\hline$D$ & Stiff soil & $180-360 \mathrm{~m} / \mathrm{sec}$ \\
\hline E & Soft clays & $<180 \mathrm{~m} / \mathrm{sec}$ \\
\hline$F$ & $\begin{array}{l}\text { Special study soils, for example, liquefiable soils, sensitive } \\
\text { clays, organic soils, soft clays }>36 \mathrm{~m} \text { thick }\end{array}$ & \\
\hline
\end{tabular}


histories. To achieve high resolution of the near-surface stratigraphy, seismogram inversion is employed to weak-motion recordings (Assimaki et al., 2006). Also, the scarcity of ground-motion recordings is addressed by generating a suite of synthetic ground motions for rupture scenarios of weak, medium, and large magnitude events ( $M$ 3.5-7.5). Approximate and incremental nonlinear models are implemented, and site-response observations are initially compared to the ensemble site-response estimates. Parametric studies are next conducted for each fixed magnitude scenario by varying the source-to-site distance, and the variability introduced in ground-motion predictions is quantified for each nonlinear site-response methodology. A frequency index is developed to describe the frequency content of incident ground motion relative to the resonant frequencies of the soil profile, and this index is used in conjunction with the rock-outcrop acceleration peak amplitude $\left(\mathrm{PGA}_{\mathrm{RO}}\right)$ to identify the site conditions and ground-motion characteristics where incremental nonlinear analyses should be employed in lieu of approximate methodologies. Finally, site-amplification factors are computed for the alternative site-response methodologies and compared to published site factors of attenuation relations to illustrate the role of site-response analyses in the development of hybrid attenuation relations based on recorded as well as synthetic ground motions.

\section{Site Conditions at Three Strong-Motion Geotechnical Arrays in the Los Angeles Basin}

Figure 1 depicts the locations of the three instrumented geotechnical downhole arrays in southern California investigated in this study that are operated by the Southern California Earthquake Center (SCEC) and the California Strong-Motion Instrumentation Program (CSIP). Geotechnical data available at these stations comprise downhole and suspension logging shear-wave velocity profiles $\left(V_{s}\right)$, as well as scarce laboratory resonant column modulus reduction $\left(G / G_{\max }\right)$ and damping $(\xi)$ versus shear-strain amplitude curves from samples extracted at a few locations in the near surface.

A detailed description of the near-surface stratigraphy is achieved by employing the seismogram inversion algorithm developed by Assimaki et al. (2006) to weak ground motions recorded at the three arrays (Table 2). This optimization technique comprises a genetic algorithm in the wavelet domain coupled to a nonlinear least-squares fit in the frequency domain, and it has been shown to improve the computational efficiency of the former while avoiding the pitfalls of using local linearization techniques such as the latter (Houck et al., 1996). The parameters estimated are stepwise variations of the shear-wave velocity, attenuation, and density with depth for horizontally layered media with predefined layer thickness. Deterministic lower and upper bounds were imposed on the vector of unknowns to constrain the search space, based on independent geological and geotechnical sitecharacterization data. (a)

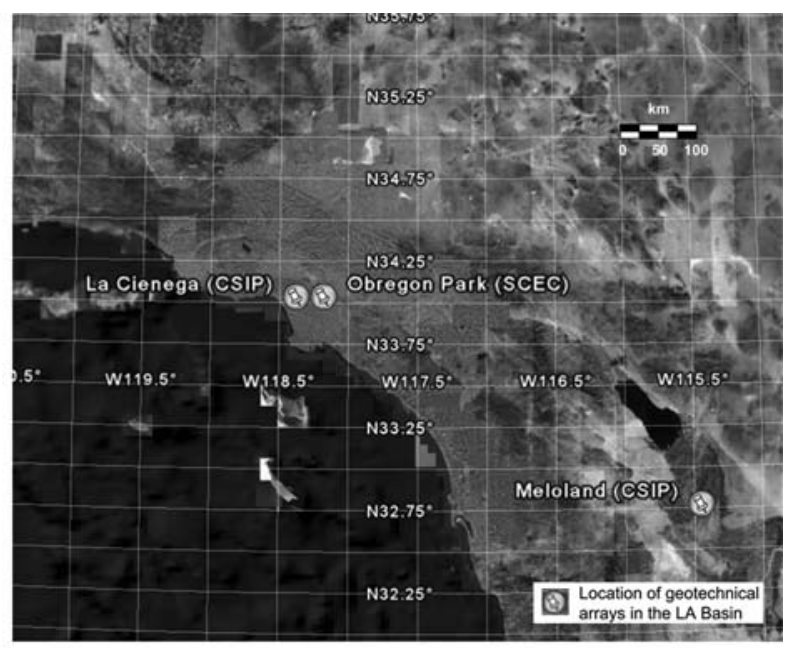

(b)
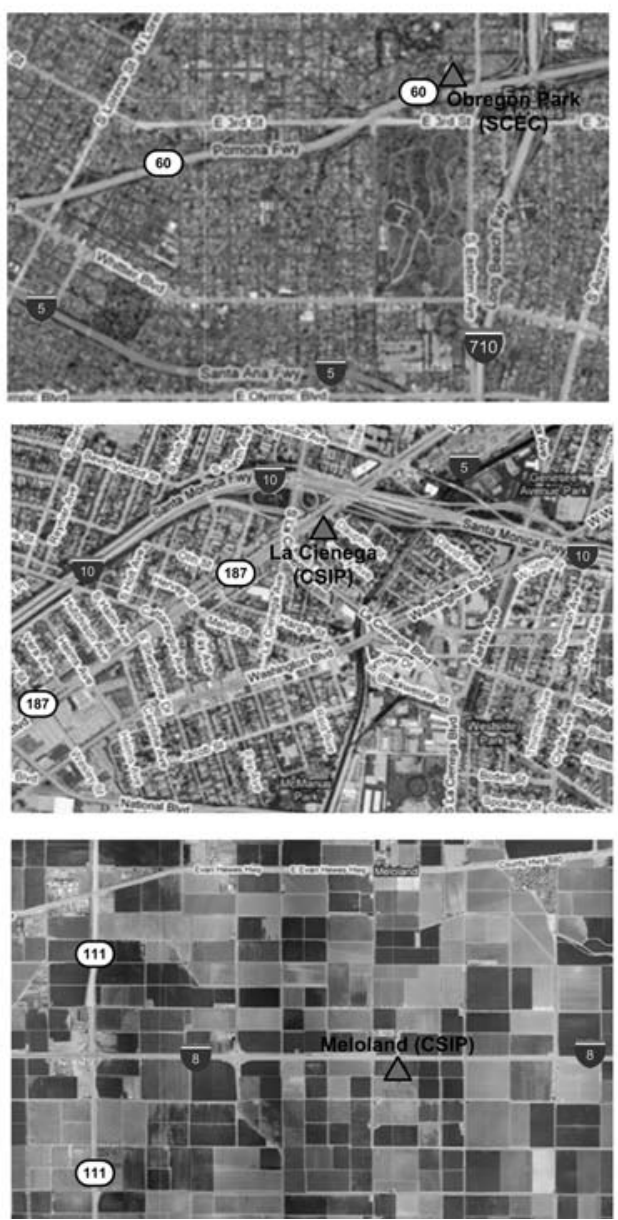

Figure 1. (a) Satellite map depicting the location of strong-motion geotechnical arrays (SMGA) in the Los Angeles basin investigated in this study and (b) detailed maps of SMGA locations in the Los Angeles basin. Seismogram inversion results based on weakmotion recordings are shown in Figure 2.

For the global optimization scheme, the objective function is defined as the normalized correlation between observed data and synthetics as follows (Stoffa and Sen, 1991): 
Table 2

Strong-Motion Geotechnical Array Stations in the Los Angeles Basin

\begin{tabular}{lcccccc}
\hline \multicolumn{1}{c}{ Station Name } & Latitude $\left(^{\circ}\right)$ & Longitude $\left(^{\circ}\right)$ & Agency & Station Depth $(\mathrm{m})$ & Geology & NEHRP Site Class \\
\hline Obregon Park (CE.K400) & 34.037 & -118.178 & SCEC & 0,70 & $Q$ & $C$ \\
Los Angeles -La Cienega Geotechnical Array & 34.036 & -118.378 & CSIP & $0,18,100,252$ & Deep alluvium & $D$ \\
El Centro-Hwy8/Meloland Overpass & 32.773 & -115.447 & CSIP & $0,30,100,252$ & Deep alluvium & $E$ \\
\hline
\end{tabular}

Coordinates, operating agencies (CSIP represents the California Strong-Motion Instrumentation Program; SCEC stands for the Southern California Earthquake Center), location of downhole receivers, and geology description of the station locations $(Q$ represents Quaternary).

$$
\begin{aligned}
C(m)= & \frac{1}{N_{p}} \sum_{1}^{N_{p}}\left[2 \sum_{1}^{N_{\mathrm{TS}}} a_{0} a_{s}^{*}(m)\right] /\left[\left(\sum_{1}^{N_{\mathrm{TS}}} a_{0} a_{0}^{*}\right)\right. \\
& \left.+\left(\sum_{1}^{N_{\mathrm{TS}}} a_{s}[m] a_{s}^{*}[m]\right)\right],
\end{aligned}
$$

where $a_{0}, a_{s}(m)$ are the observed and synthetic seismograms, respectively, $N_{\mathrm{TS}}$ is the number of time steps (TS), and $N_{p}$ is the number of wavelet decomposition bands of the signal. Decomposing the signal in the wavelet domain and normalizing the approximation and details-as opposed to the original signal-in the objective function definition allows for equal weighting of the information across all frequency bands, an approach preferable to a time-domain representation that would inevitably emphasize the larger amplitude signals of the nonstationary ground motion in time and frequency.

Further accelerating the convergence of the optimization scheme, a local improvement operator is employed at the end of the selection process of each generation. In particular, a nonlinear Gauss-Newton scheme is employed, forcing the active parental generation to convergence to local minima or maxima prior to mutation, crossover, and reproduction. This technique, referred to as the hill-climbing method of local optimization, has been shown to significantly enhance the performance of genetic algorithms (Stoffa and Sen, 1991; Houck et al., 1996). The objective function of the nonlinear least-squares optimization is defined in the frequency domain, as the energy error between the model and data vectors:

$$
E(m)=\left(\sum_{1}^{N_{\omega}}\left[A_{0}-A_{s}^{*}(m)\right]^{2}\right) /\left(\sum_{1}^{N_{\omega}} A_{0}^{2}+\sum_{1}^{N_{\omega}}\left[A_{s}^{*}(m)\right]^{2}\right),
$$

where $A_{0}, A_{s}(m)$ are the empirical and theoretical transfer functions, respectively, and $N_{\omega}$ is the number of frequencies.

For each array, the algorithm was repeated in a series for multiple borehole and surface waveform pairs, selected on the basis of their available signal-to-noise ratio (SNR). Averaging of the optimal solution for multiple events has been shown to minimize the error propagation of the measured process and the error translation of the forward idealized model limitations, leading to a robust estimate of the bestfit solution to the inverse problem. For more information, the reader is referred to Assimaki et al. (2006) and Assimaki and Steidl (2007).

The averaged inverted profiles of shear-wave velocity $\left(V_{s}\right)$, attenuation $(Q)$, and density $(\rho)$ at the three arrays are illustrated in Figure 2a, along with the available onsite suspension logging and cross-hole velocity data. Two points should be highlighted in reference to the inversion results:

1. Overall, the inverted $V_{s}$ profiles compare well with the in-situ geotechnical data with the exception of a few layers, such as the 15-m layer at 60-m depth at Meloland Strong-Motion Geotechnical Array (SMGA). Nonetheless, seismogram inversion evaluated at the three sites using multiple low intensity events showed low scatter of depth-dependent soil properties, while the limited in-situ geotechnical data had no redundancy. As a result, the inverted profiles were implemented in the site-response simulations described in the ensuing. A typical example of implementation is shown in Figure $2 b$, where the ground surface response computed from the inverted soil parameters and the response computed using the in-situ geotechnical data are compared to the recorded ground motion at Meloland SMGA during an $M 5.1$ event not used in the inversion process; as can be readily seen, the former predictions compare better with the observations.

2. The attenuation profiles $(Q)$ in the near surface show a wide statistical distribution, attributed to the forward model operator where the physical configuration is idealized by a stack of horizontally stratified homogeneous layers subjected to vertically propagating antiplane shear waves. This model cannot properly account for the strong scattering of high-frequency components in the naturally heterogeneous near-surface soil layers, and it attributes the late arrivals of noncoherent redistributed energy to energy loss. As a result, inverted $Q$-values in the nearsurface are both lower than the material energy absorption measured in the laboratory and strongly motion dependent for wavelengths comparable to typical correlation lengths of the heterogeneous formations.

Finally, one-dimensional (1D) crustal compressional velocity $\left(V_{p}\right)$, shear velocity $\left(V_{s}\right)$, and density models $(\rho)$ were extracted from the 3D Southern California Community 

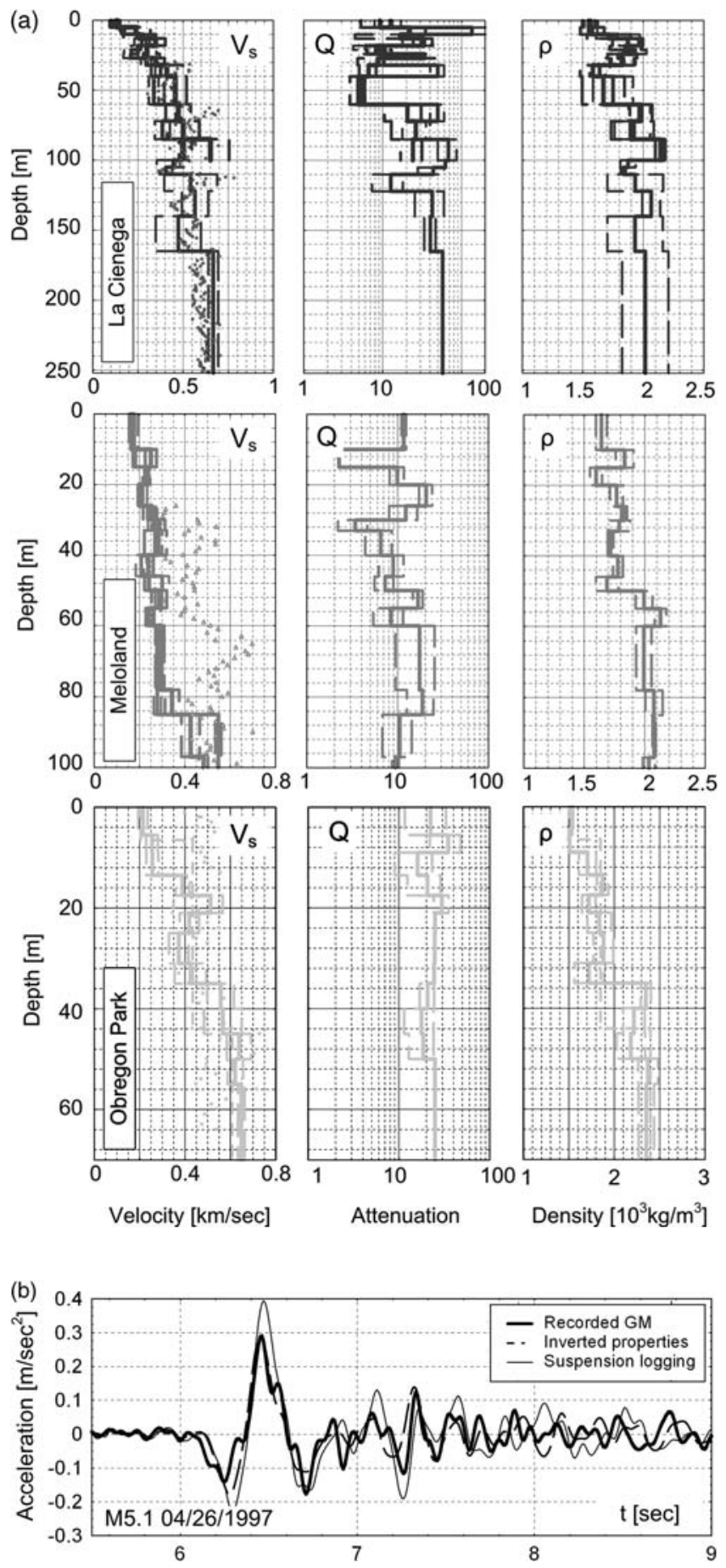

Figure 2. (a) Velocity $\left(V_{s}\right)$, attenuation $(Q)$, and density $(\rho)$ evaluated by means of downhole array seismogram inversion at three SMGA stations in the LA basin (depicted in Fig. 1). Figure 2b illustrates an example of site-response analyses conducted using the available geotechnical data and inverted profiles at the La Cienega SMGA. (b) Comparison between ground response observations and predictions for weak ground-motion data recorded at Meloland SMGA. Linear elastic site-response analyses conducted based on the suspension logging and best-fit soil properties from seismogram inversion of multiple events illustrate that the available geotechnical data at the site would lead to a $25 \%$ error in the estimation of the ground surface response.
Velocity Model IV (SCEC CVM IV, http://www.data.scec .org/3Dvelocity/) at the locations of the three arrays (Fig. 3). Serving as a unified reference model for several areas of research in southern California, the shallow sediment velocities in the CVM IV model are taken from geotechnical borehole measurements, the bedrock velocities are based on tomographic studies, and the deeper sediment velocities are obtained from empirical relationships that take into account the age of the formation and depth of burial, calibrated to sonic logs taken from boreholes in the region.

The SCEC CVM IV crustal models (Fig. 3) were used for the simulation of broadband ground-motion synthetics that were next deconvolved to the base of the soil profiles for the site-specific ground response analyses. This incident motion was propagated through the best-fit low-strain profiles shown in Figure 2a; using the limited information on nonlinear soil properties $\left(G / G_{\max }\right.$ and $\left.\xi\right)$ available, the nonlinear site response of the three soil profiles was estimated as a function of the site, ground motion, and methodology implemented. The steps of this procedure are described in detail in the following sections.

\section{Broadband Ground-Motion Simulations}

Strong ground-motion synthetics were computed for multiple rupture scenarios over a wide range of epicentral distances for the development of a statistically significant set of ground motions in terms of intensity and frequency content. The broadband ground-motion synthetics were simulated for multiple strike-slip fault rupture scenarios over a $100 \times 100-\mathrm{km}^{2}$ square grid (Fig. 4) by means of the hybrid low-frequency/high-frequency approach with correlated source parameters (Liu et al., 2006).

In this approach, broadband ground-motion synthetics are calculated by separately computing the low- and highfrequency components. In particular, low-frequency components $(<1 \mathrm{~Hz})$ are evaluated by means of a 3D velocity model implemented in the viscoelastic, fourth-order, finitedifference (FD) algorithm of Liu and Archuleta (2002); highfrequency ground motions (<e.g., 10-20 Hz) are generated using a layered velocity model (1D) and the frequencywavenumber (FK) code by Zhu and Rivera (2001). A realistic attenuation model is common to both the 3D and 1D calculations that form the low- and high-frequency components of the broadband synthetics, in which the value of $Q$ is a function of the local shear-wave velocity, while the accuracy of high-frequency amplitudes and durations is enhanced by correction of the 1D synthetics with a randomized frequencydependent radiation pattern that employs a frequencydependent perturbation of strike, dip, and rake on each subfault (Liu et al., 2006) (Fig. 5).

It should be noted, however, that the crossover frequency between low-frequency 3D FD simulations and highfrequency 1D FK realizations is approximately $1 \mathrm{~Hz}$, while the length scale of interest of this study is on the order of $100 \mathrm{~m}$ in the near surface. As a result, 3D effects are unlikely 

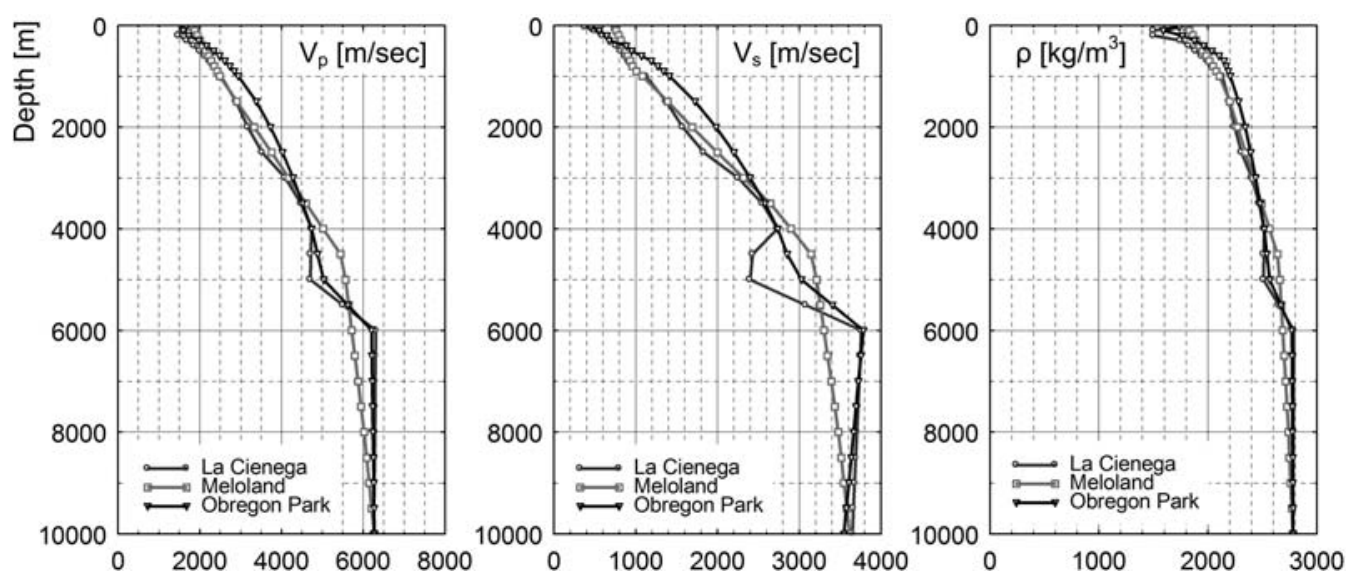

Figure 3. One-dimensional crustal compressional $\left(V_{p}\right)$ and shear $\left(V_{s}\right)$ velocity and density $(\rho)$ models extracted from the Southern California Community Velocity Model III at the three stations investigated in this study and implemented in the broadband ground-motion synthetic simulations.

to affect the near-surface response of nonlinear soil formations because they correspond to wavelengths longer than the total depth of the simulated profiles. Thus, taking advantage of the computational efficiency of 1D simulations for the evaluation of high-frequency synthetics, the 3D groundmotion components were omitted for the purpose of this study, and the 1D crustal models in Figure 3 were used to generate synthetic time histories. Successively, the broadband ground-motion synthetics were corrected for local site and nonlinear soil effects by a series of nonlinear models by linear deconvolution of the surface ground motion to a sufficient depth; propagation of the incident motion to the surface was corrected by means of the alternative nonlinear models

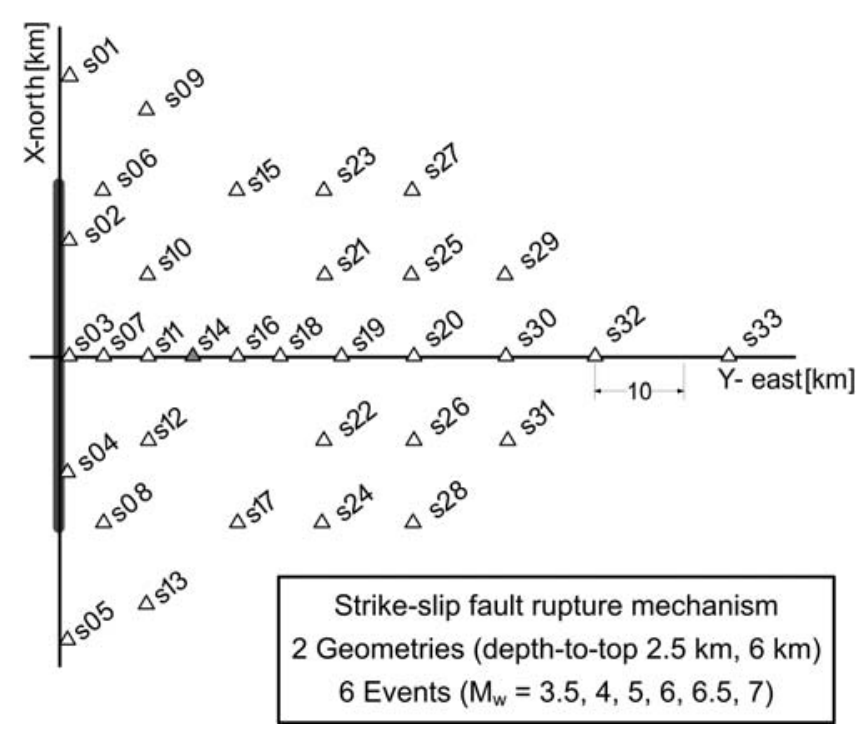

Figure 4. Station layout over a $100 \times 100 \mathrm{~km}^{2}$ grid where broadband ground-motion time histories were evaluated for a series of strike-slip rupture scenarios corresponding to two fault geometries and six magnitudes by means of the hybrid low-frequency/ high-frequency approach with correlated source parameters (Liu et al., 2006). and the available geotechnical information. A schematic representation of the approach described previously is illustrated in Figure 6.

\section{Strong-Motion Site-Response Analyses: Modeling and Numerical Implementation}

The engineering community has long believed that sediment nonlinearity is significant, a perspective that has been widely confirmed based on laboratory studies (Seed and Idriss, 1970b; Hardin and Drnevich, 1972a,b; Seed et al., 1984; Drnevich et al., 1996) where observed stress-strain loops implied a reduced effective shear modulus and an increased material energy absorption (damping) at higher levels of strain (Fig. 7). This relationship has been shown to describe the in-situ soil response to earthquake loading as well, and site-response calculations need to accommodate these strain dependencies through nonlinear constitutive relations. Currently, two approaches are conventionally used to model cyclic soil-response, equivalent-linear, and nonlinear models. The models are briefly described in the ensuing sections and successively implemented for the prediction of nonlinear site response at the three SMGA in the LA basin.

\section{Equivalent-Linear Models}

The equivalent-linear approach, introduced by Seed and Idriss (1970b), approximates a second-order nonlinear equation by a linear operator by defining a characteristic strain that is assumed to be constant for the duration of the excitation. Moduli and damping curves (Fig. 7) are then used to define new parameters for each layer. The linear response calculation is repeated, new characteristic strains evaluated, and iterations are performed until convergence. This stepwise analysis procedure has been formalized into a computer code termed SHAKE (Schnabel et al., 1972), which currently is the most widely used analysis package for $1 \mathrm{D}$ site-specific response calculations. The advantages of the equivalent- 

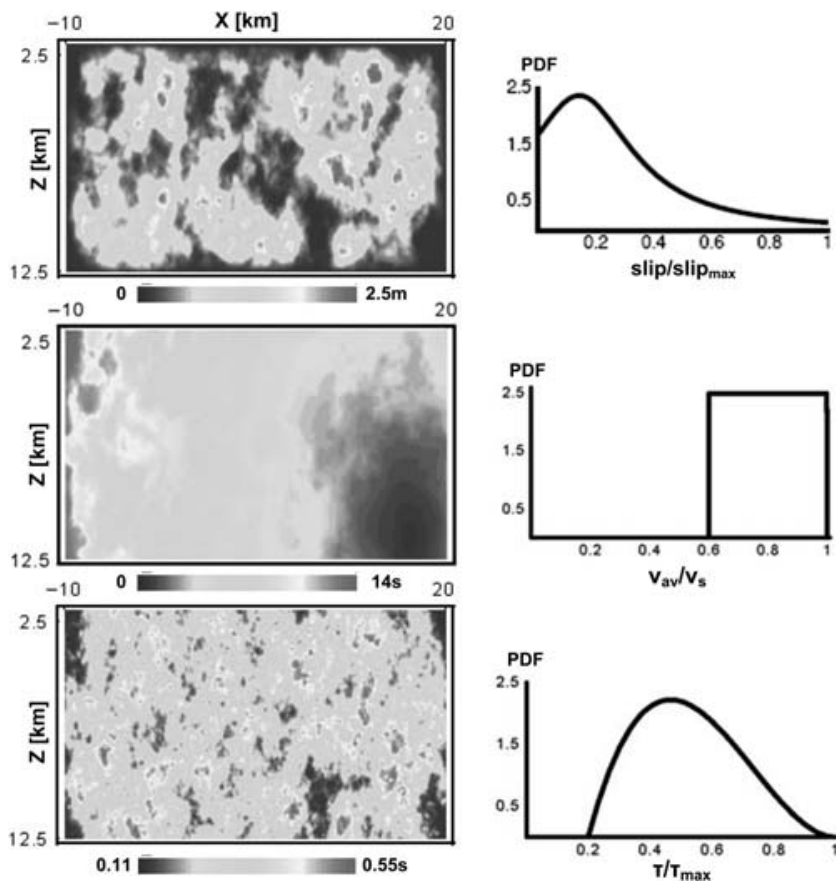

Figure 5. Typical realization of the random distribution of slip, rupture velocity, and stress drop over the fault, located $2 \mathrm{~km}$ below the ground surface simulated by means of the hybrid low-frequency/ high-frequency approach with correlated source parameters (Liu et al., 2006).

linear approach are that the mathematical simplicity of linear analysis is preserved and the determination of nonlinear parameters is avoided.

Despite the effectiveness of the approach for the analysis of relatively stiff sites subjected to intermediate levels of strain $\left(<10^{-3}\right)$, however, the equivalent-linear method has been shown to overestimate the peak ground acceleration for large events and artificially suppress the high-frequency components when applied for the analysis of deep sites. An alternative methodology that accounts for the frequency dependence of strain amplitudes and associated dynamic soil properties has been proposed by Assimaki and Kausel (2002), and it has been shown to yield more satisfactory results for deep sedimentary deposits; the applicability of the alternative formulation, however, is still limited to the medium strain levels (Hartzell et al., 2004).

The linear stress-strain material behavior and total stress approach associated with equivalent-linear models entirely prohibit their use for problems that involve large levels of strain (e.g., near-fault motions), deep and/or soft, and very soft sedimentary sites. Both the original formulation of the equivalent-linear method and the frequency-dependent modified algorithm are being implemented in the ensuing for ground surface response analyses to the ensemble of ground-motion time histories; the divergence of their predicted response from the incremental nonlinear analyses is reported to illustrate their range of applicability for the site conditions under investigation.

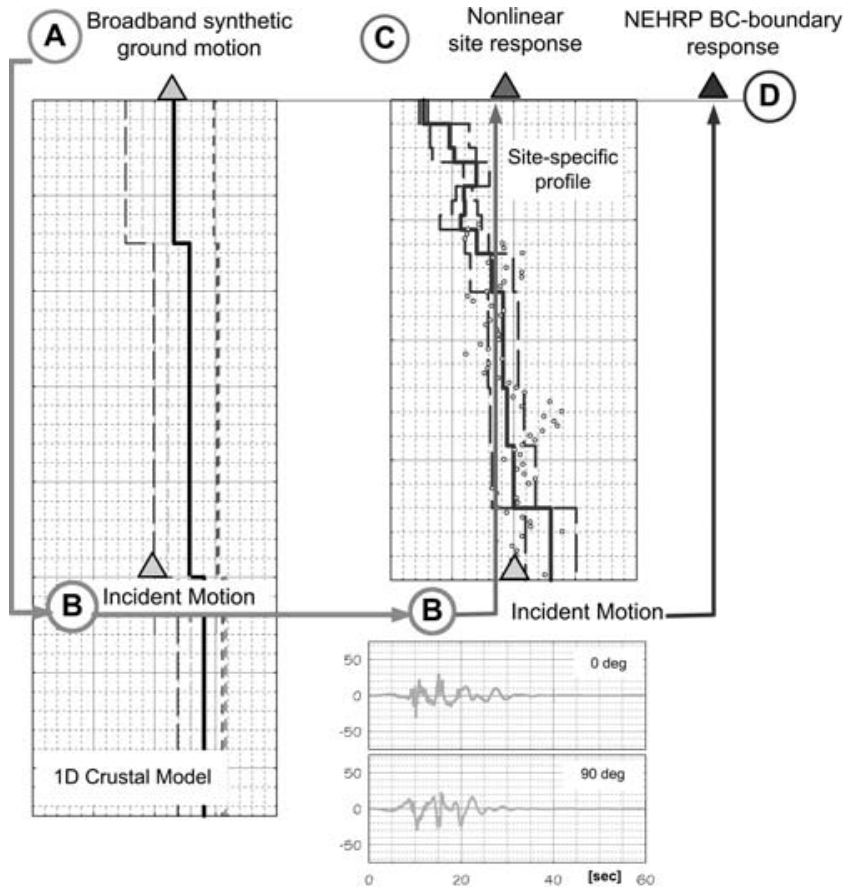

Figure 6. Schematic representation of the algorithm implemented for the assessment of nonlinear site-response modeling uncertainty in broadband ground-motion simulations at three strongmotion geotechnical arrays in the Los Angeles basin.

Nonlinear Models: Monotonic Stress-Strain

Response and Hysteretic Behavior

In the nonlinear formulations of transient soil behavior, the wave equation is directly integrated in the time domain, and the material properties are adjusted to the instantaneous levels of strain and loading path according to the mathematical description of nonlinear stress-strain model and hysteretic (loading and unloading) soil response. As a result, nonlinear constitutive models can simulate soil behavioral features unavailable in the equivalent-linear formulation such

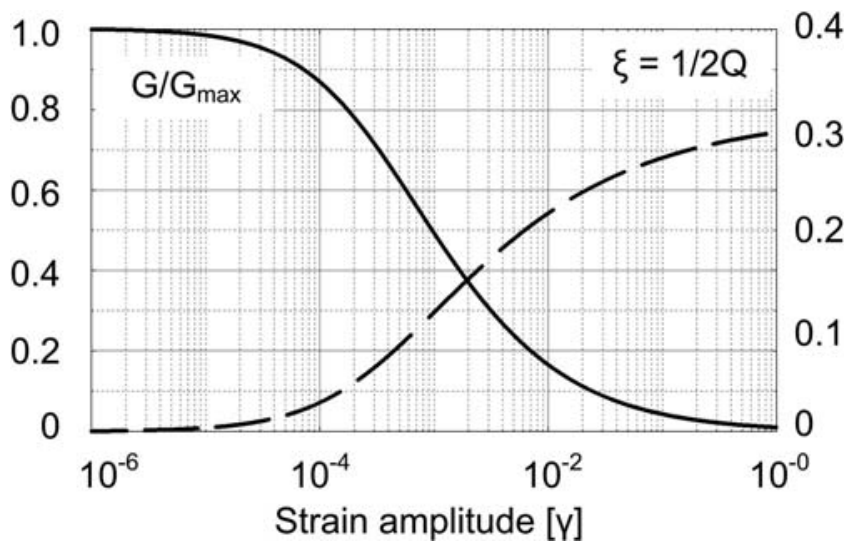

Figure 7. Typical modulus degradation $\left(G / G_{\max }\right)$ and damping $(\xi)$ versus cyclic shear-strain amplitude $(\gamma)$, characteristic of nonlinear soil response. 
as updated stress-strain relationships and/or cyclic modulus degradation, which are critical for the prediction of largestrain problems at soft sedimentary sites.

Nonlinear simulations were evaluated by means of the central difference method as described in Bardet (2001). Figure 8 illustrates schematically the geometry and boundary conditions of the response simulations conducted for a horizontally stratified system of homogeneous layers extending horizontally to infinity and subjected to vertically propagating horizontally polarized shear waves.

Five alternative monotonic idealizations of the constitutive soil behavior were investigated in this study, which are listed in the following paragraphs with increasing degrees of complexity in terms of the input parameters required, referred to as the multilinear, the hyperbolic (Ishihara, 1996), the Ramberg-Osgood (R-O) (Faccioli et al., 1973; Streeter et al., 1974), the modified hyperbolic (Matasovic and Vucetic, 1993, 1995), and the generalized hyperbolic (Hayashi et al., 1992) models. These constitutive relations were coded in a finite-difference scheme, and their effectiveness was assessed by comparison of their predictions with SMGA observations. A brief description of their formulation follows:
1. In the multilinear model, the monotonic stress-strain relationship is derived by direct integration of the target modulus reduction curve, $\tau_{i}=G_{i} \gamma_{i}$, where $G_{i}=$ $G_{\max } G_{i}^{\prime}, \tau_{i}$ is shear stress, $\gamma_{i}$ is shear strain, $G_{i}$ is the secant shear modulus, $G_{i}^{\prime}$ is the $i$ th normalized shear modulus value of the modulus reduction curve, and $G_{\max }$ is the initial tangent shear modulus. Successively, the damping ratio $\xi_{i}$ at shear-strain amplitude $\gamma_{a}=\gamma_{i}$ can be expressed as

$$
\xi_{i}=\frac{2}{\pi}\left(\left[\sum_{j=2}^{i}\left(G_{j} \gamma_{j}+G_{j-1} \gamma_{j-1}\right)\left(\gamma_{j}-\gamma_{j-1}\right)\right] / G_{i} \gamma_{i}^{2}-1\right)
$$

The multilinear model can be calibrated to match exactly the experimental modulus reduction at all levels of strain, yet the predicted damping is found to overestimate the laboratory measured data at high levels of strain $(>0.1 \%)$.

2. The idealized soil stress-strain response of the hyperbolic model is bounded by two straight lines tangential to it at small and large strains correspondingly (Ishihara, 1996).
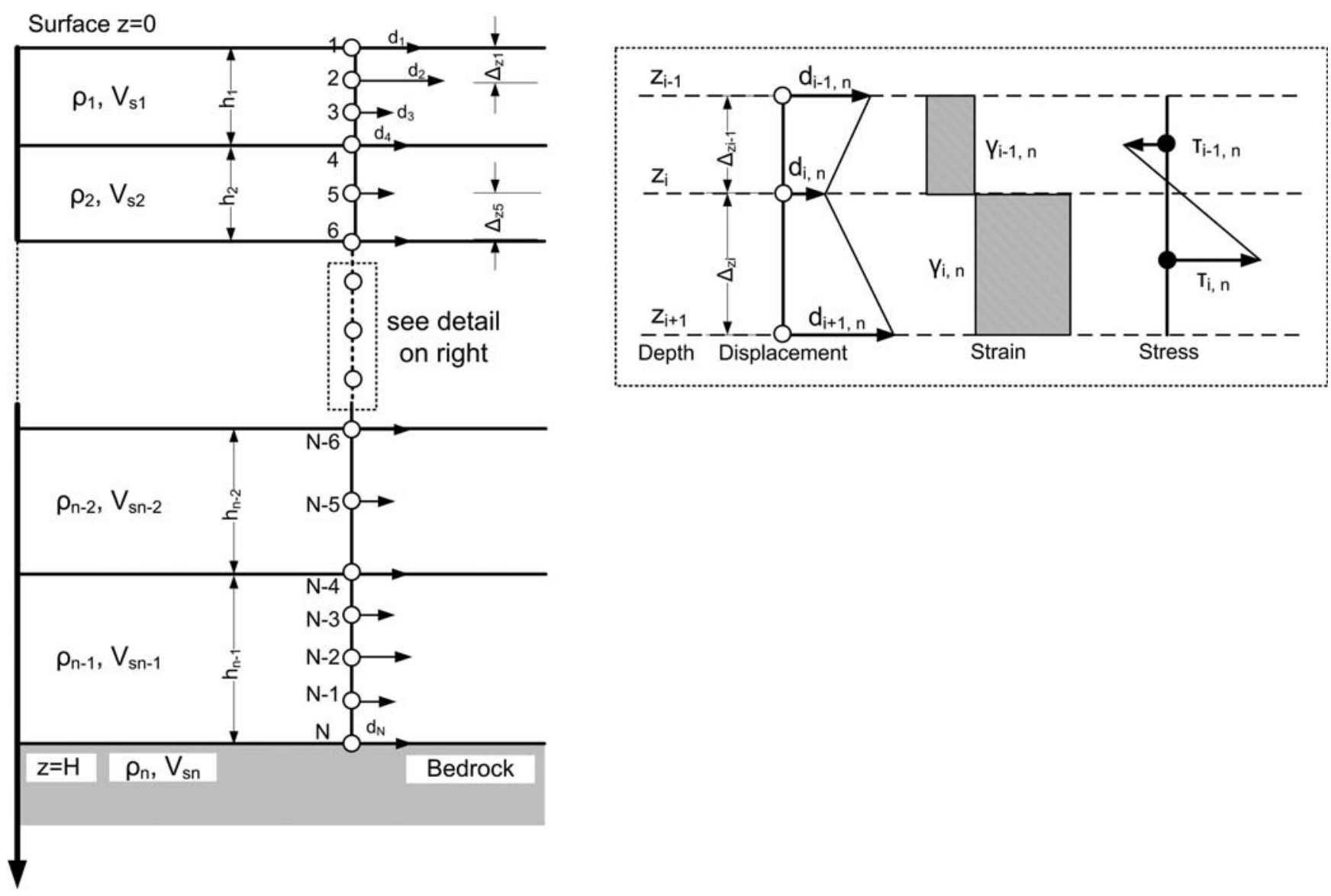

Figure 8. Schematic representation of spatial discretization for a one-dimensional soil deposit system, along with the detail illustrating the definition of displacement, strain, and stress in the finite-difference formulation. The displacement $d$ and stress $\tau$ are evaluated at $N$ grid nodes, which define sublayers within layers. The displacement of node $i$ at time step $t_{n}$ is denoted $d\left(z_{i}, t_{n}\right)=d_{i}, n$, where $z_{i}$ is the depth of node $i$. Similarly, the stress and strain at node $i$ at time step $t_{n}$ are denoted $\tau_{i, n}$ and $\gamma_{i, n}$ (modified from Bardet, 2001). 
The tangent at small strains is denoted by $G_{\max }$ and represents the elastic modulus at small strains, and the horizontal asymptote at large strains indicates the shear strength of the material $\tau_{\max }$. The stress-strain curve for the hyperbolic model (Kondner and Zelasko, 1963; Duncan and Chang, 1970) can be expressed as follows:

$$
\tau=G_{\max } \gamma /\left(1+\frac{\gamma}{\gamma_{r}}\right)
$$

where the parameter $\gamma_{r}$, which is the so-called reference strain and is defined as $\gamma_{r}=\tau_{\max } / G_{\max }$, indicates a strain that would be attained at the shear strength if a soil were to behave elastically, as shown in Figure 9a. Successively, the damping ratio of the hyperbolic model may be expressed as
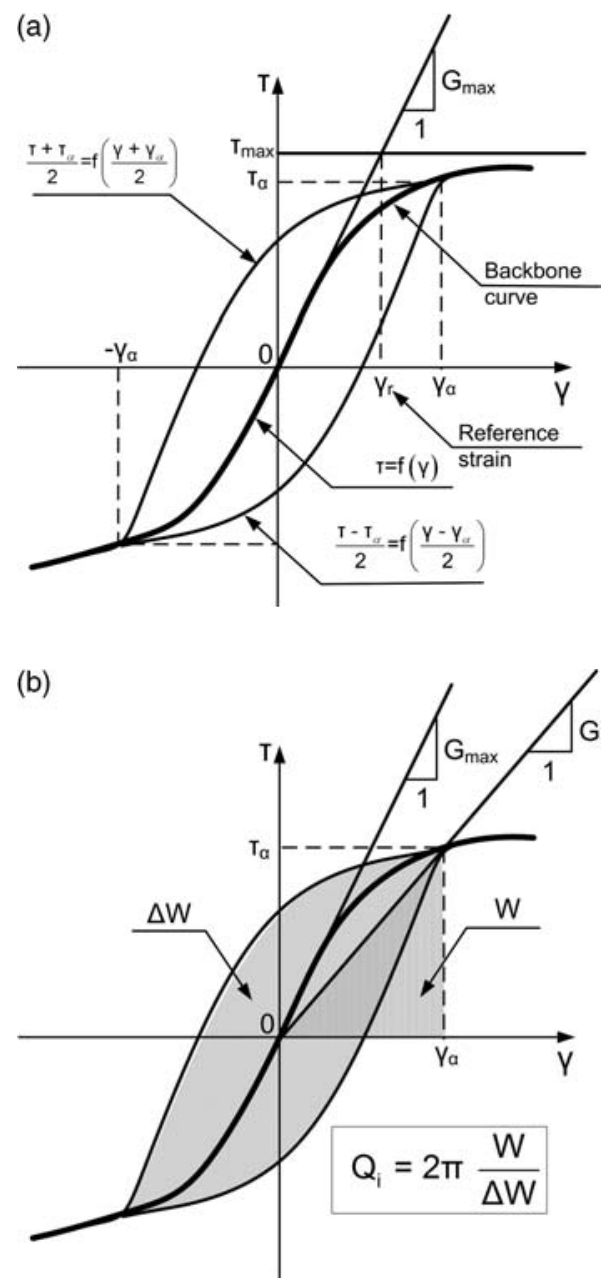

Figure 9. (a) Schematic representation of original Masing unloading-reloading criteria and definition of reference strain and stress reversal point of the hysteresis loop and (b) schematic representation of secant shear modulus $(G)$, elastic stored strain energy $(W)$ and dissipation energy $(\Delta W)$, and definition of hysteretic intrinsic attenuation $Q_{i}$.

$$
\xi=\frac{4}{\pi} \frac{1}{1-G / G_{\max }}\left[1+\frac{G / G_{\max }}{1-G / G_{\max }} \ln \left(\frac{G}{G_{\max }}\right)\right]-\frac{2}{\pi} .
$$

The limited number of parameters of the hyperbolic model $\left(G_{\max }\right.$ and $\left.\tau_{\max }\right)$ does not typically allow the fitting of experimentally determined modulus reduction and damping. In particular, when the reference strain $\gamma_{r}$ is specified from the strain-dependent characteristics of the secant shear modulus, the value of the straindependent damping ratio is automatically determined, and there is no parameter to be adjusted and give a good fit to the obtained experimental damping data that are overestimated at high-strain levels $(>0.1 \%)$.

3. The modified hyperbolic model (referred to as MKZ) is an extension of the hyperbolic model proposed by Matasovic and Vucetic (1993, 1995), which uses the following modified hyperbolic formulation as initial (backbone) loading:

$$
\tau=\left(G_{\max } \gamma\right) / 1+\beta\left(\frac{\gamma}{\gamma_{r}}\right)^{s}
$$

The MKZ model has three independent fitting parameters $\left(\gamma_{r}, \beta\right.$, and $\left.s\right)$ and is therefore much more flexible to be calibrated in fitting the experimental data both for the modulus reduction and damping ratio curves. Despite the versatility of the model, the shear strain increases in proportion to the shear stress for large strains, a drawback that prohibits the use of the model for large levels of strain at which the soil is anticipated to reach the level of shear strength of the material.

4. The stress-strain behavior of the Ramberg-Osgood (R-O) model is formulated as

$$
\tau=\frac{\tau_{\max }\left(\gamma / \gamma_{r}\right)}{1+\alpha\left|\frac{\tau}{\tau_{\max }}\right|^{r-1}}
$$

Similarly to the MZK model, the R-O model has three independent fitting parameters $\left(\gamma_{r}, \alpha\right.$, and $\left.r\right)$, which allows the model to be fitted to experimental data, yet because the shear strain also increases in proportion to the shear stress at large strains, the model may not be implemented at large levels of strain. The damping ratio curve has the following form:

$$
\begin{aligned}
\xi & =\frac{2}{\pi} \frac{r-1}{r+1}(\alpha) \frac{\left|\frac{G}{G_{\max }}\left(\frac{\gamma_{a}}{\gamma_{r}}\right)\right|^{r-1}}{1+\alpha\left|\frac{G}{G_{\max }}\left(\frac{\gamma_{a}}{\gamma_{r}}\right)\right|^{r-1}} \quad \text { or } \\
\xi & =\frac{2}{\pi} \frac{r-1}{r+1}\left(1-\frac{G}{G_{\max }}\right) .
\end{aligned}
$$

5. Hayashi et al. (1992) proposed a four-parameter model, referred to as the generalized hyperbolic model, which 
has more versatility to fit experimentally obtained shear stress versus shear-strain relations over a wide range of strain amplitudes by combining two modified hyperbolic models of the following form:

$$
\begin{aligned}
y & =\left[\left(\frac{2}{n} x+1\right)^{n}-1\right] /\left[\left(\frac{2}{n} x+1\right)^{n}+1\right] \\
& =f(x, n),
\end{aligned}
$$

namely, $y=f\left(x, n_{L}\right)$ and $y=f\left(x, n_{U}\right)$ in a quasilinear way by means of an additional parameter $\alpha$ that controls how $y$ transfers from $f\left(x, n_{L}\right)$ to $f\left(x, n_{U}\right)$ with increasing $x$ as follows:

$$
y=e^{-\alpha x} f\left(x, n_{L}\right)+\left(1-e^{-\alpha x}\right) f\left(x, n_{U}\right) .
$$

Therefore, the backbone curve of this model may be expressed as:

$$
\tau=G_{\max } \gamma_{r}\left\{g(\alpha) f\left(x_{L}\right)+[1-g(\alpha)] f\left(x_{U}\right)\right\},
$$

where

$$
\begin{aligned}
& g(\alpha)=\exp \left(-\alpha \frac{\gamma}{\gamma_{r}}\right) \\
& f(x)=\left[\left(2 \frac{\gamma / \gamma_{r}}{x}\right)^{x}-1\right] /\left[\left(2 \frac{\gamma / \gamma_{r}}{x}\right)^{x}+1\right] .
\end{aligned}
$$

While the increased number of parameters allows additional versatility to fit the experimental data over a wide range of strain amplitudes, the resulting damping ratio cannot be expressed in closed form due to the complexity of the model, and fitted parameters need to be properly constrained to allow their physically sound interpretation.

For the representation of the hysteretic soil behavior in transient loading, the extended Masing rules are employed in the simulations, which comprise the two original Masing criteria (Masing, 1926) schematically illustrated in Figure 9, namely: (i) the shear modulus on each loading reversal is equal to the maximum tangent modulus of the initial loading (backbone) curve and (ii) the unloading and reloading branches of the hysteresis loop are translated and scaled replicas of the backbone (initial loading) curve by a factor constant throughout the loading time history and equal to 2.0 , as well as two additional criteria to describe the unloading and reloading branches of the hysteresis loop, namely: (iii) the unloading and reloading curves follow the backbone curve if the previous maximum amplitude of the shear strain is exceeded and (iv) if the current reloading or unloading curve intersects the curve described by a previous reloading or unloading, the stress-strain relationship follows that previous curve.

The set of rules (i)-(iv) is consistent with a series of mechanical models described by Iwan (1967), according to which the shear strain may be easily decomposed into elastic and plastic components as required by the formulation of incremental elastoplasticity. The Iwan model implemented in this study for the incremental solution of the wave equation in nonlinear media consists of a group of $N$ elastic perfectly plastic elements in parallel, each comprising a linear elastic spring and a rigid slip element connected as shown in Figure 10. The number of elastoplastic elements and corresponding stiffness and Coulomb resistance values were in each case selected to fit the target material model behavior $[\tau=f(\gamma)]$. Based on this mathematical representation originally proposed by Iwan (1967) and Mroz (1967), the multilinear shear stress-strain behavior for $N$ elastoplastic springs subjected to a strain amplitude $\gamma$ is

$$
\tau=\sum_{i=1}^{N} \frac{k_{i}}{N} \gamma+\sum_{i=n+1}^{N} \frac{\tau_{y i}}{N},
$$

where $k_{i}$ is the shear stiffness of the $i$ th element, $\tau_{y i}$ is the critical slipping (Coulomb) stress of the $i$ th element, $n$ is the number of elastoplastic elements that remain elastic upon the application of a strain increment, and $\tau$ is the estimated level of shear stress at a given level of strain amplitude $\gamma$. The first and second terms of the right-hand side of equation (12) indicate the elastic and plastic components, respectively, of the total stress $\tau$. Note that the form of the stress-strain relationship for subsequent unloading at any reversal point may be evaluated by means of the response of the three fol-
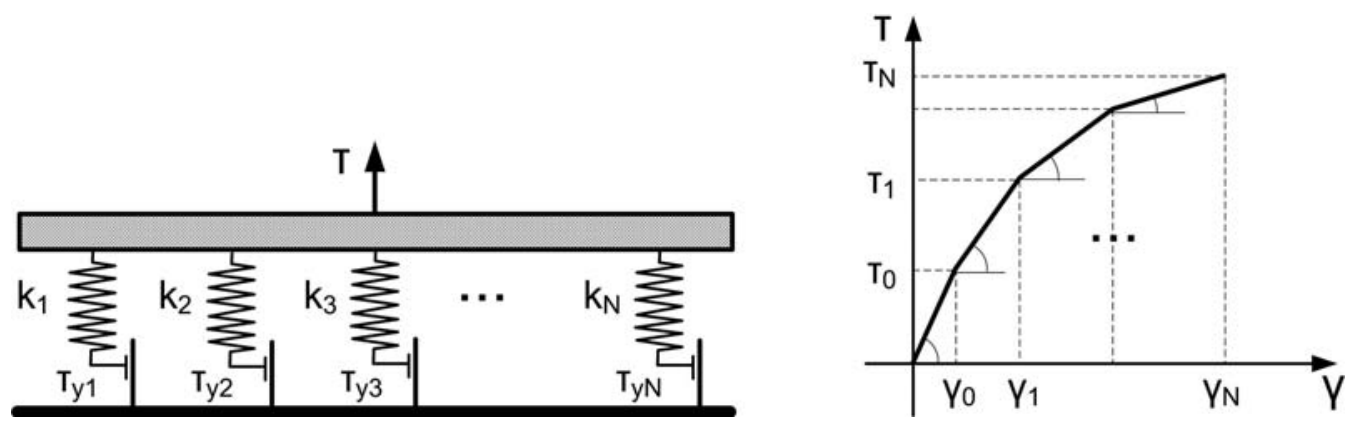

Figure 10. Iwan (1967) model of elastoplastic springs in parallel simulating the nonlinear stress-strain soil behavior and corresponding approximation of continuous backbone curve by a series of linear segments. 
lowing groups of slip elements: (i) elements that did not yield upon previous loading remain elastic, (ii) elements under the state of yielding that have stopped slipping after reversal, and (iii) elements that have yielded during loading and now yield in the opposite direction. As can be readily seen, the Iwan model provides a very convenient tool for the simulation of soil behavior that is consistent with the extended Masing rules and was thus selected for the purpose of this work. More specifically, 500 elastoplastic elements were used to ensure the accuracy of the simulated soil-response to highfrequency transient loading.

\section{Simulation of Small-Strain}

Frequency-Independent Damping

Energy loss through nonelastic process is usually measured by intrinsic attenuation and parameterized with the quality factor $Q$. Incorporation of seismic $Q$ in the groundmotion modeling is important because it can strongly affect the amplitude and duration of the ground motion when waves travel within shallow soft materials. When the wave equation is solved in the time domain (e.g., finite differences) given a nonlinear stress-strain formulation, material absorption is replicated by the hysteretic unloading-reloading cycles when the material is subjected to strain amplitudes beyond the linear elastic range. Nonetheless, frequency-independent material absorption is also observed in the laboratory when the soil is subjected to very low-strain amplitudes, heretofore referred to as low-strain damping.

The most widely used implementation of low-strain damping in strong ground-motion modeling is Rayleigh damping, a formulation also used in finite element modeling of structural dynamics for the representation of energy loss mechanisms in structures (Bao et al., 1998). Also known as proportional damping, Rayleigh damping is formulated on the assumption that the damping matrix $([C])$ of a system is a linear combination of the mass $[M]$ and stiffness $[K]$ matrices as follows:

$$
[C]=\alpha[M]+\beta[K]
$$

where the coefficients $\alpha$ and $\beta$ are computed to give the required levels of attenuation at two different frequencies (Chopra, 2000. The Rayleigh damping formulation is very computationally efficient, yet may be only implemented in a narrow frequency band for frequency-independent target $Q$, as shown in Figure 11. An extended formulation of Rayleigh damping, referred to as Caughey damping, may be implemented to fit the target $Q$-values at more than two frequencies. Hashash and Park (2002) employed Caughey damping for the nonlinear site-response analysis in Mississippi embayment. In their formulation, the choice of significant frequencies/modes was optimized by comparison with the viscoelastic solution in the frequency domain (Park and Hashash, 2004). Recently, Kwok et al, (2007) used theoretical wave propagation solutions to provide guidelines for the

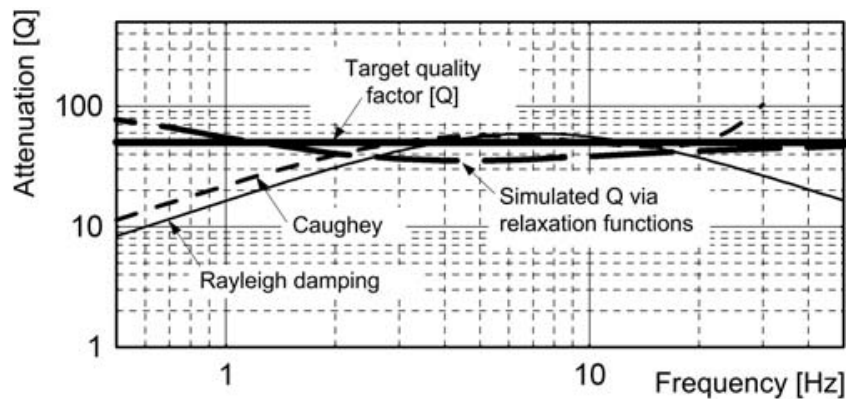

Figure 11. Typical example of target low-strain damping (intrinsic attenuation) simulation by means of the Rayleigh damping formulation, the Caughey damping, and the memory-variable technique (Liu and Archuleta, 2006) implemented in this study.

definition of material attenuation in site-response analyses, and they concluded that the target frequencies should be established through a process by which linear time-domain and frequency-domain solutions are matched; as a first approximation, the first-mode site frequency and five times that frequency was suggested.

Alternatively, the target low-strain material attenuation may be fitted via time-domain wave-field simulations by the memory-variable technique originally described by Day and Minster (1984) and successively implemented by both Emmerich and Korn (1987) and Carcione et al. (1988). This technique can be implemented to accurately model both a frequency-independent and frequency-dependent $Q$ over a wide frequency range by using a linear combination of multiple relaxation mechanisms (e.g., Liu and Archuleta, 2006). Each relaxation mechanism is represented by a set of memory variables that can be updated using first-order differential equations, while the accuracy of modeling $Q$ depends on the number of relaxation mechanisms used, namely, more relaxation mechanisms will result in a more accurate modeling of $Q$.

The memory-variable representation of frequencyindependent $Q$ was implemented in the simulations of nonlinear site response, and it was incorporated in the time-domain simulations based on the rheology formulation of a generalized Maxwell body, modified here as follows:

$$
\tau(t)=G\left[\gamma(t)-\sum_{k=1}^{N} \varsigma_{k}\right]
$$

where $\zeta_{k}$ are memory variables that correspond to the solution of the following first-order set of differential equations, with $\tau_{k}$ being the relaxation times and $w_{k}$ being the weight coefficients:

$$
\tau_{k} \frac{d \varsigma_{k}(t)}{d t}+\varsigma_{k}(t)=w_{k} \gamma(t)
$$

The accuracy of low-strain damping modeling depends on the accuracy of estimation of $\tau_{k}$ and $w_{k}$. The nonlinear simulations in this article were evaluated by means of the 
empirical interpolating algorithm proposed by $\mathrm{Ma}$ and Liu (2006). The suggested values for $\tau_{k}$ and $w_{k}$ are shown in Table 3. The weight coefficients $w_{k}^{\xi}$ for a target value of damping ratio $\xi$ are calculated using the interpolation formula,

$$
w_{k}^{\xi}=\chi\left(\chi \alpha_{k}+\beta_{k}\right),
$$

where the values of $\alpha_{k}$ and $\beta_{k}$ are also listed in Table 3. Finally, the factor $\chi$ depends only on the target value of $\xi$ and is estimated by the following expression:

$\chi=\left[3.071+1.433\left(\frac{1}{2 \xi}\right)^{-1.158} \ln \left(\frac{1}{10 \xi}\right)\right] /\left[1+\frac{0.2075}{\xi}\right]$.

An example of implementation of equation (17) within the context of a time-domain direct integration of the wave equation is shown in Figure 11 for a target value of low-strain material damping $\xi=0.01$ (or $Q=50$ ), and the effectiveness of this formulation may be readily seen by comparison to the Rayleigh damping and higher-order Caughey damping formulations.

\section{Calibration of Nonlinear Soil Parameters}

For each one of the nonlinear models, the input parameters were selected to optimally fit the available experimental data of soil modulus reduction and damping versus shearstrain amplitude. For this purpose, a genetic algorithm was implemented, with objective function targeted to simultaneously minimize the square error between the measured and theoretically predicted modulus reduction and damping data as follows:

$$
\begin{aligned}
& \sum_{i=1}^{N}\left\{w_{i}\left[O_{G}\left(\gamma_{i}\right)-G\left(P, \gamma_{i}\right)\right]\right\}^{2} \\
& +\sum_{j=1}^{N}\left\{w_{j}\left[O_{\xi}\left(\gamma_{j}\right)-\xi\left(P, \gamma_{j}\right)\right]\right\}^{2},
\end{aligned}
$$

where $w_{i}$ and $w_{j}$ are the weight coefficients of the global search, $O_{G}\left(\gamma_{i}\right)$ and $O_{\xi}\left(\gamma_{j}\right)$ are the $i$ th and $j$ th experimental

Table 3

Relaxation Coefficients for Modeling Frequency-Independent Small-Strain Damping $(Q)$

\begin{tabular}{ccrc}
\hline$k$ & $\tau_{k}$ & \multicolumn{1}{c}{$\alpha_{k}$} & $\beta_{k}$ \\
\hline 1 & $1.72333 \times 10^{-3}$ & $1.66958 \times 10^{-2}$ & $8.98758 \times 10^{-2}$ \\
2 & $1.80701 \times 10^{-3}$ & $3.81644 \times 10^{-2}$ & $6.84635 \times 10^{-2}$ \\
3 & $5.38887 \times 10^{-3}$ & $9.84666 \times 10^{-3}$ & $9.67052 \times 10^{-2}$ \\
4 & $1.99322 \times 10^{-2}$ & $-1.36803 \times 10^{-2}$ & $1.20172 \times 10^{-1}$ \\
5 & $8.49833 \times 10^{-2}$ & $-2.85125 \times 10^{-2}$ & $1.30728 \times 10^{-1}$ \\
6 & $4.09335 \times 10^{-1}$ & $-5.37309 \times 10^{-2}$ & $1.38746 \times 10^{-1}$ \\
7 & 2.05951 & $-6.65035 \times 10^{-2}$ & $1.40705 \times 10^{-1}$ \\
8 & 13.2629 & $-1.33696 \times 10^{-1}$ & $2.14647 \times 10^{-1}$ \\
\hline
\end{tabular}

points for the modulus reduction and damping curves at $\gamma_{i}$ and $\gamma_{j}$ strain amplitudes correspondingly, and $G\left(P, \gamma_{i}\right)$ and $\xi\left(P, \gamma_{j}\right)$ are the corresponding predicted values as a function of the model parameters $P$. In particular for the representation of small-strain intrinsic attenuation, the experimentally measured value was subtracted from the damping curve prior to the stochastic search because the evaluation of anelastic intrinsic attenuation is only a function of the modulus reduction function. Successively, for each model investigated, the small-strain damping was implemented in the finitedifference formulation by means of the memory-variable technique described previously, a formulation yielding a frequency-independent intrinsic attenuation across the frequency and strain spectra of interest.

An example of the fitted modulus reduction and damping versus shear-strain curves for the ensemble of idealized nonlinear stress-strain behaviors investigated in this study is shown in Figure 12 along with the predicted stress-strain hysteresis loops for a material with the illustrated nonlinear response and initial shear modulus, $G_{\max }=10^{4} \mathrm{k} \mathrm{pa}$, subjected to a series of cyclic-strain time histories with increasing amplitude. The modulus reduction and damping curves illustrated in this figure correspond to the nonlinear material properties at the La Cienega SMGA, as estimated from laboratory experiments conducted on samples extracted at depth $7.5 \mathrm{~m}$ (http://geoinfo.usc.edu/rosrine/ project_IMS/query/rosrine_site_list.asp).

\section{Nonlinear Site-Response Observations versus Synthetics}

The strong-motion site-response models described previously were initially bench marked for weak ground motions by comparison with downhole array recordings. Successively, the limited number of strong-motion recordings at the three sites was used to quantify the error introduced in the predictions by the alternative formulations and to identify a proxy for the observed site response to be used as the reference prediction in the synthetic groundmotion simulations.

A typical example of a medium intensity event ( $M 4.2$, peak ground acceleration $[\mathrm{PGA}]=0.22 g$ ) recorded at $\mathrm{La}$ Cienega SMGA is shown in Figure 13, where predictions are compared to the time history and response spectrum of the recorded motion on ground surface. Nonetheless, the intensity of ground motion is not sufficient to produce strong nonlinear effects in the near surface, and as a result, both the equivalent-linear formulation and the nonlinear incremental analyses yield results within $20 \%$ deviation in the predicted PGA (Fig. 13a). Similar conclusions are drawn from the response spectra of the alternative models shown in Figure 13b and the hysteresis loops predicted by the ensemble of nonlinear models at depth $7.5 \mathrm{~m}$ from ground surface depicted in Figure 13c.

Next, the cumulative normalized error between the observed and predicted spectral accelerations was defined as: 
(a)

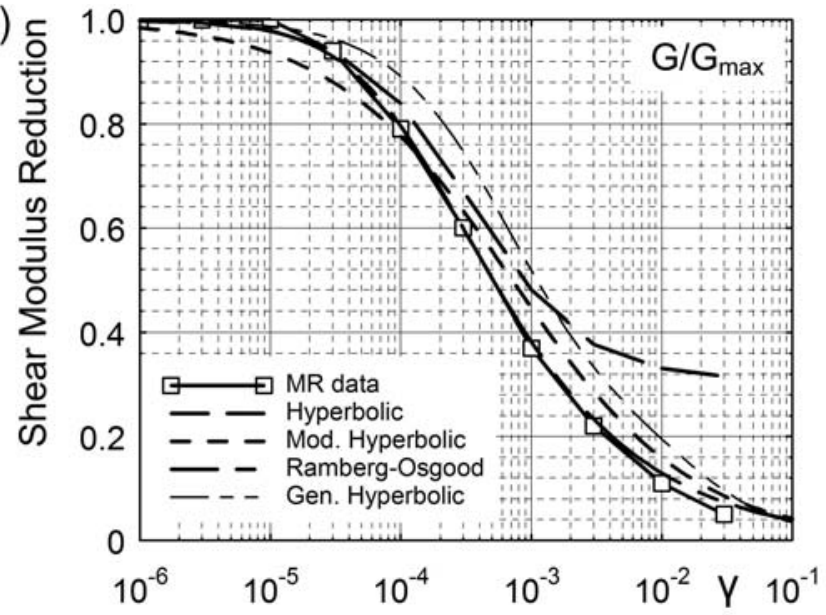

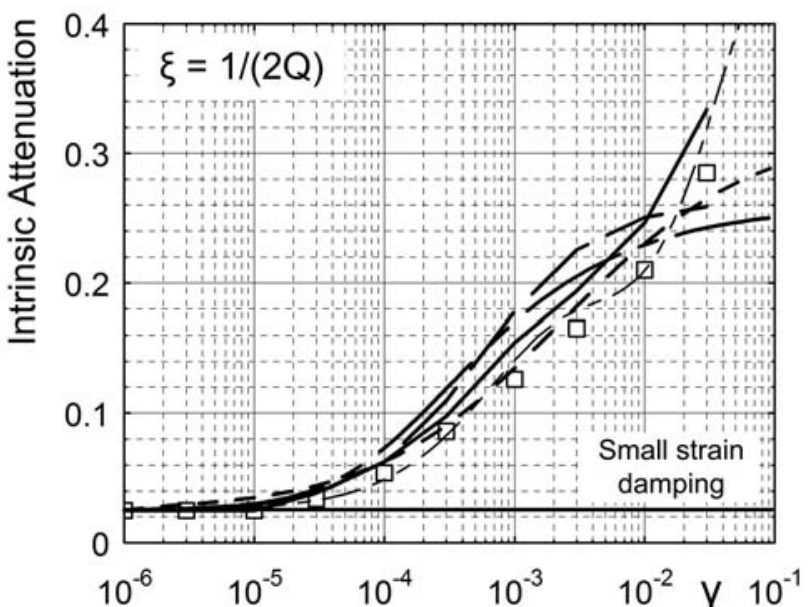

(b)

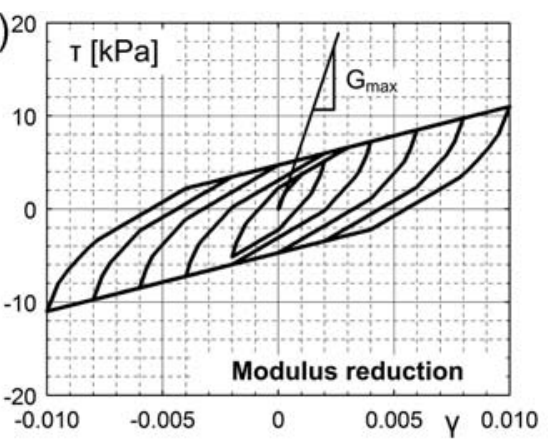

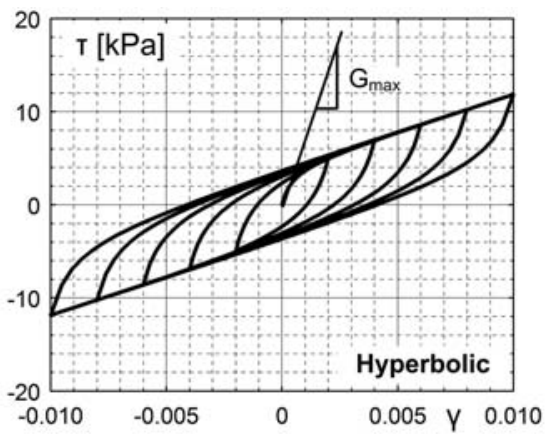

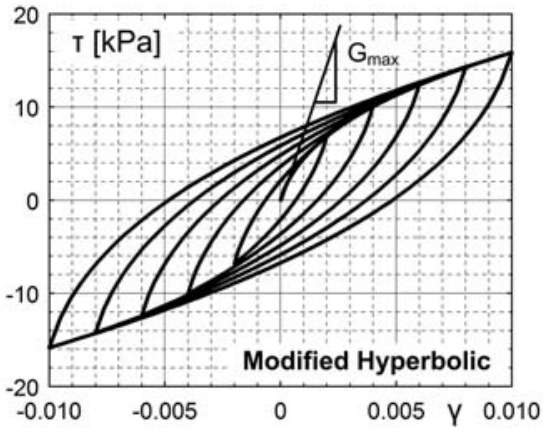

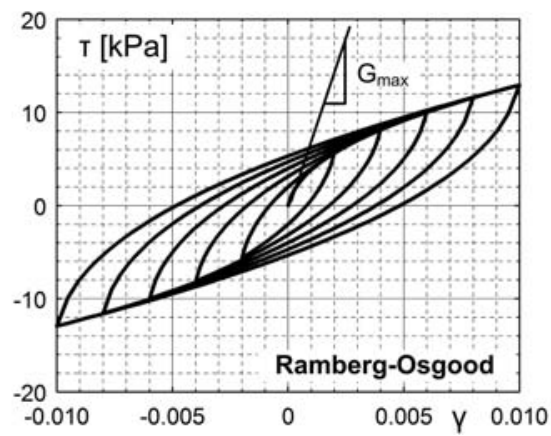

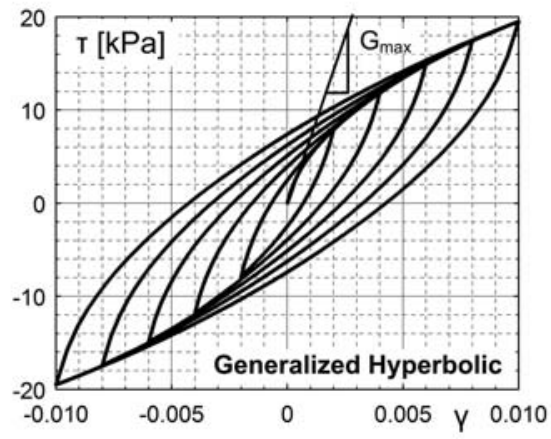

Figure 12. (a) Example of fitted modulus reduction and damping versus shear-strain curves for the ensemble of idealized nonlinear stress-strain behaviors investigated in this study and (b) predicted stress-strain hysteresis loops for a material with the illustrated nonlinear response and initial shear modulus $G_{\max }=104 \mathrm{kPa}$, subjected to a series of cyclic-strain time histories with increasing amplitude.

$$
e_{S A}=\frac{1}{n} \sqrt{\sum_{i=1}^{n}\left[\frac{S A_{o}\left(T_{i}\right)-S A_{p}\left(T_{i}\right)}{S A_{o}\left(T_{i}\right)}\right]^{2}}
$$

where $S A_{o}$ and $S A_{p}$ are the observed and predicted spectral acceleration values at period $T_{i}$, and $i=1 \ldots n$ is the number of points computed in the response spectrum. Evaluating the error between predictions and observations for the ensemble of ground motions recorded at the three sites showed that the average nonlinear response spectrum yields the closest representation of the observed response. This results from the variability in soil-response idealization via the alternative formulations that, when averaged, lead to an optimally real- istic representation of the true site response to strong ground motion for the site conditions at the three SMGA. Figure 14 shows the error estimation versus the observed PGA on ground surface, which is here used as an index of the ground-motion intensity. As can be readily seen, the error of the average nonlinear predictions is $e_{S A}<20 \%$, practically independent of the ground-motion intensity, while as expected, the prediction error of the linear elastic operator is proportional to the amplitude of PGA.

The variability in predicted motions via the nonlinear models, however, is shown to increase with the motion intensity, which is attributed to the differences in the idealizations of the stress-strain material response that become 
(a)
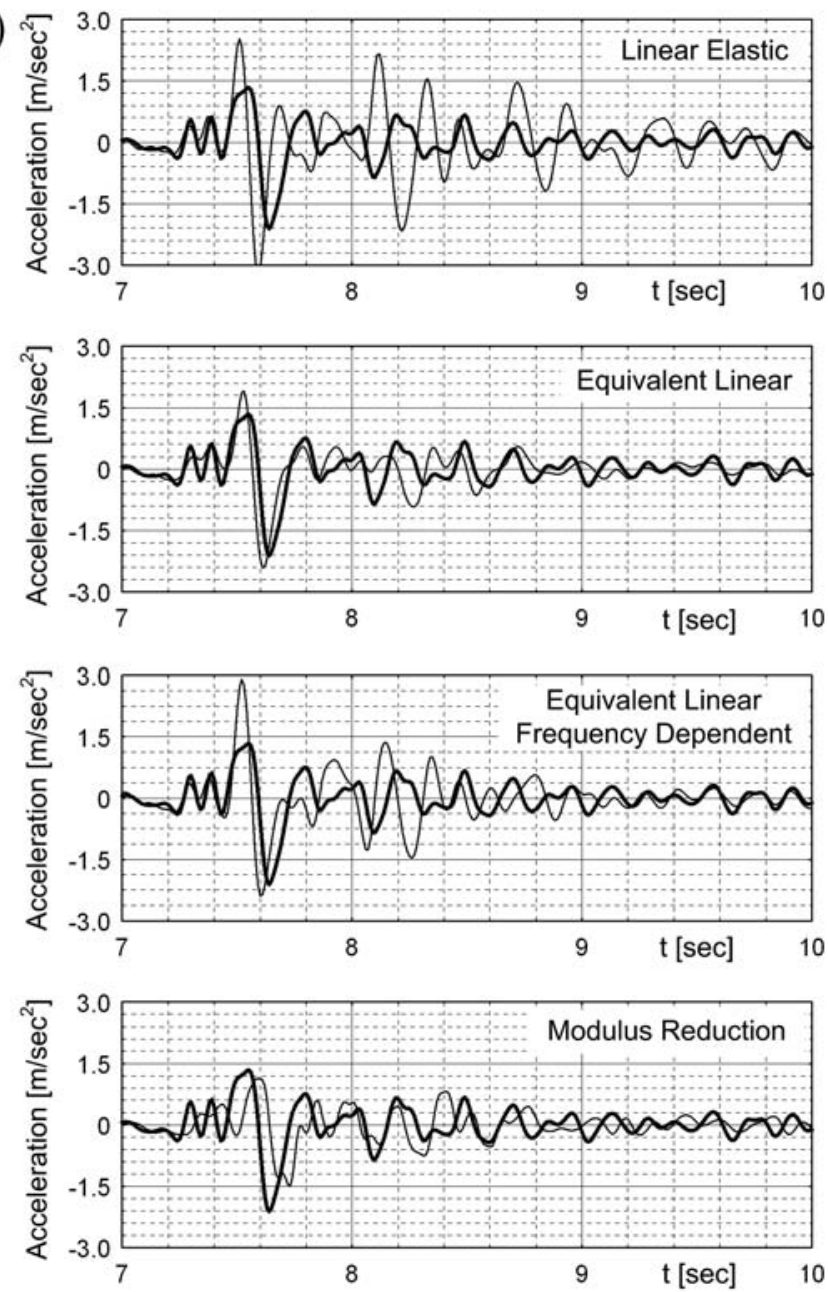
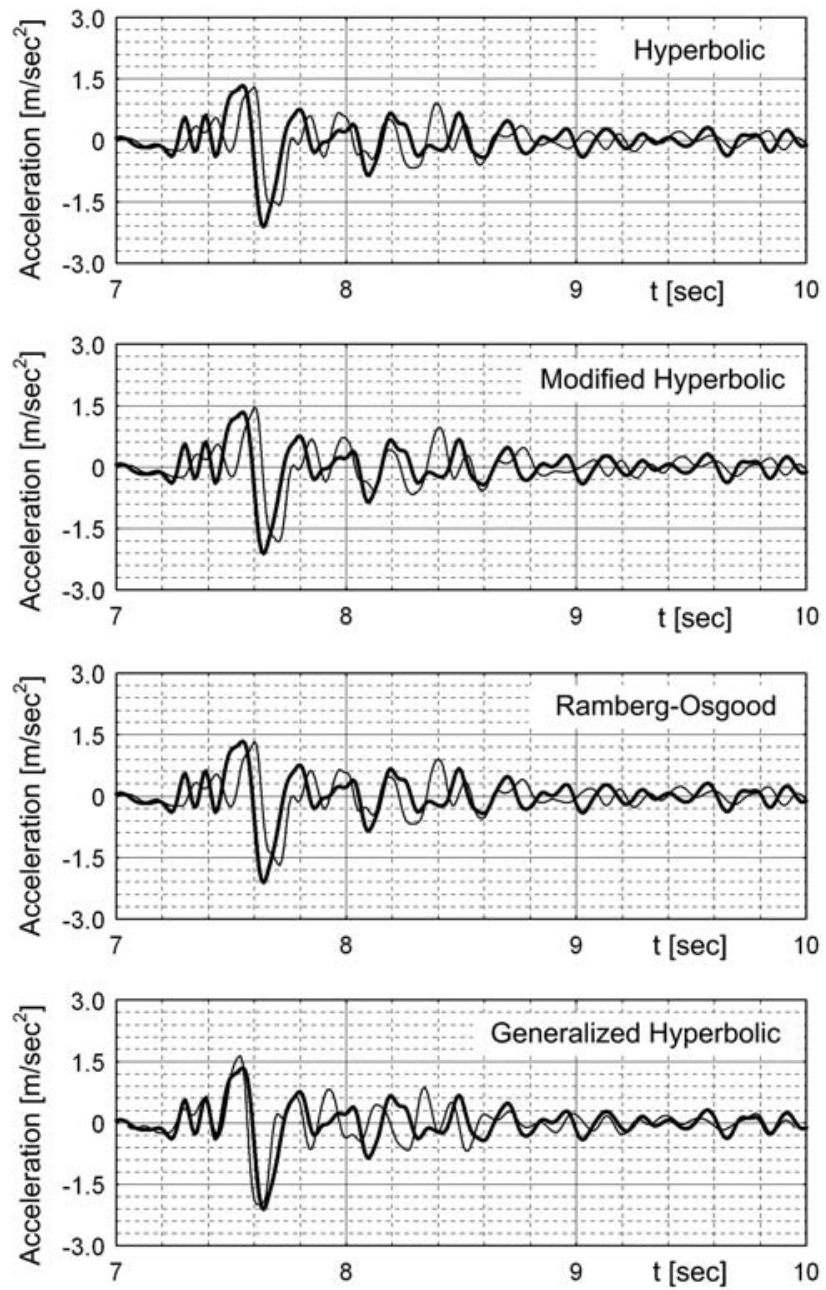

Figure 13. Comparison between observations and predictions of strong ground motion at the La Cienega SMGA during the 9 September $2001 M 4.2$ event, using the ensemble of approximate and nonlinear site-response models investigated in this work: (a) ground surface acceleration record and (b) spectral acceleration at ground surface. Also shown are the averaged \pm 1 standard values across the two groups of methodologies used to simulate strong-motion site response and (c) predicted hysteresis loops by the ensemble of nonlinear models at depth $7.5 \mathrm{~m}$ from the ground surface.

(Continued)

more pronounced with increasing strain amplitude, namely increasing motion intensity. An example is illustrated in Figure 15a that depicts the synthetic response of the soil profile at Meloland to the fault-normal component of synthetic ground motion evaluated for an $M 7.5$ event at distance $5 \mathrm{~km}$ from the surface projection of the fault (station s07 in Fig. 3). As can be readily seen, the variance of nonlinear predictions of surface ground motion is very pronounced and, for example, the PGA predicted by the hysteretic model is approximately $80 \%$ higher than the average nonlinear PGA prediction. This discrepancy is explained by Figure 15b, which shows the hysteresis loops computed via the ensemble of models at depth $7.5 \mathrm{~m}$ from ground surface. As can be readily seen, the modulus reduction and damping curves fitted by a simple hyperbola lead to significant overestimation of the shear strength of the material at very large strains, which corresponds to more pronounced elastic response than the nonlinear formulations with a larger number of fitting parameters.

\section{Nonlinearity Susceptibility and Modeling as a Function of the Site Conditions and Ground-Motion Characteristics}

The effects of nonlinear model selection in groundmotion simulations have been recently investigated by various researchers, and published studies have primarily focused on the New Madrid seismic zone (NMSZ), a region of high seismic hazard and low seismicity where the response of sedimentary deposits has been shown to be critical in the prediction of future earthquake scenarios. Among others, Park (2003) and Park and Hashash (2005) developed an integrated probabilistic seismic-hazard analysis procedure that incorporated nonlinear site effects (PSHA-NL), where 

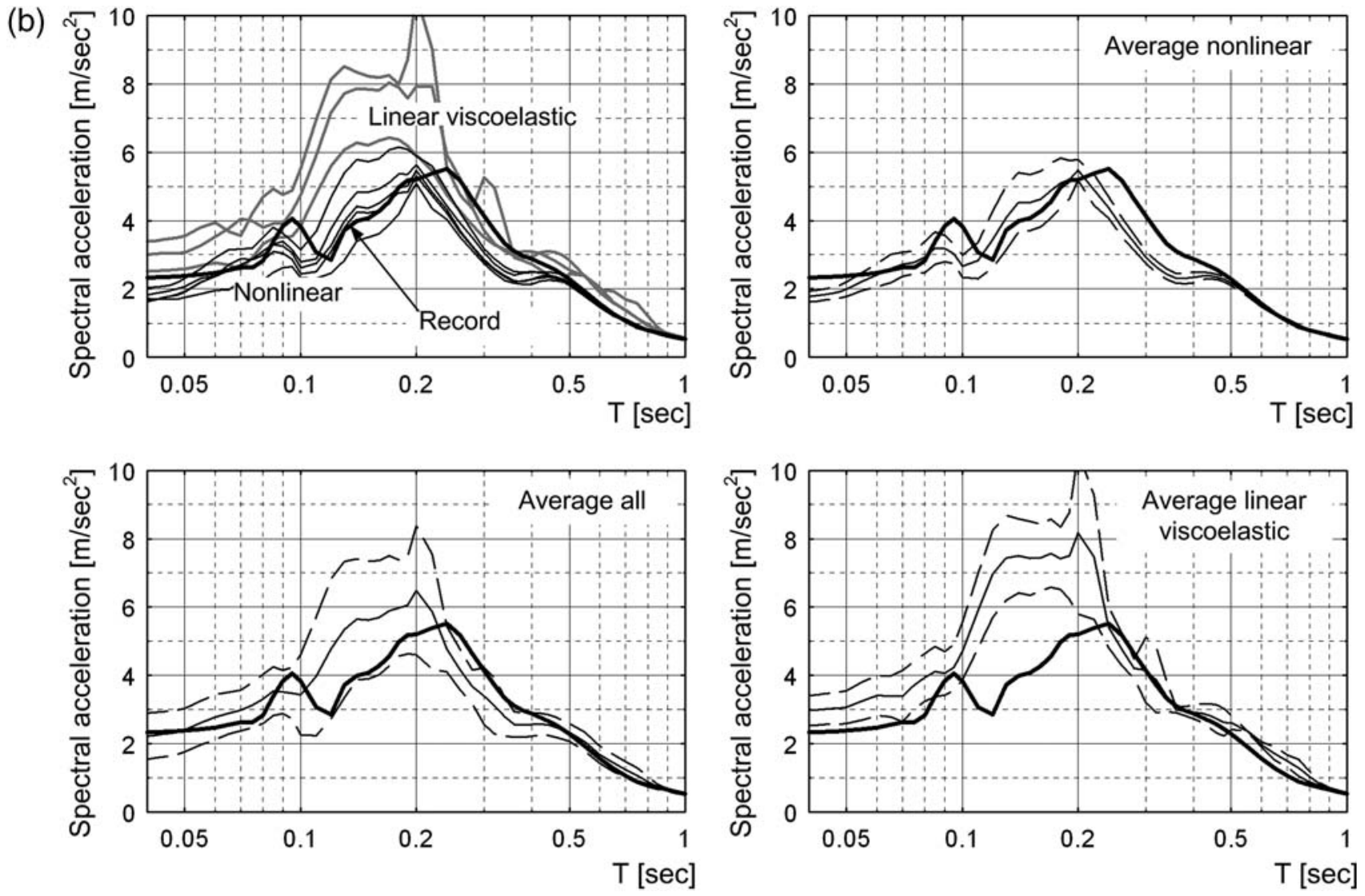

Figure 13. Continued.

site effects were directly accounted for by propagating the motions using nonlinear and equivalent-linear site-response analyses. Cramer et al. (2004) generated a suite of seismichazard maps for Memphis, Shelby County, Tennessee that account for the site response of sediments in the Mississippi embayment (ME), where the strong-motion sediment response was simulated by the equivalent-linear computer code SHAKE91 (Idriss and Sun, 1992), as well as by implementing the nonlinear site-response codes DEEPSOIL (Hashash and Park, 2001, 2002) and TREMORKA (Kausel and Assimaki, 2002; L. F. Bonilla, personal comm., 2003). They showed that SHAKE91 overly damps the high-frequency components of motion and that DEEPSOIL has a lower high-frequency response than TREMORKA. They reported that uncertainty in site amplification primarily arose from uncertainties in the site-specific dynamic soil properties and the choice of nonlinear code used to calculate site response. Although uncertainties have not been quantified, preliminary work showed that the median site response predicted by different algorithms may differ by $50 \%$ for the same set of input parameters.

Successively, Cramer (2006) combined the methodology by Cramer et al. (2004) with the reference profile approach of Toro and Silva (2001) to better estimate seismic hazard in the ME. Improvements over previous approaches included using the 2002 national seismic-hazard model, fully probabilistic hazard calculations, calibration of site amplification with improved nonlinear soil-response estimates, and estimates of uncertainty. In addition to the aforementioned computer codes, the nonlinear finite-difference code NOAH (Bonilla, 2001; Bonilla et al., 2004) was examined for implementation in the site-amplification distribution calculation procedure. In this study, Cramer (2006) quantified the added uncertainty in site-amplification estimates due to the choice of soil-response program, and results suggested a range of 20\%-50\% for PSHA ground-motion hazard estimates. He added that if this uncertainty were to be incorporated into a site-amplification logic tree, site-amplification distribution variability would be increased and site-specific PSHA values would likely increase, in particular, at low probabilities of exceedance $(<0.001)$.

In this study, the alternative site-response models are used to predict the synthetic ground surface motion, evaluate the relative uncertainty introduced by the model selection, quantify the nonlinearity susceptibility of the three sites, and suggest the optimal prediction methodology of nonlinear site effects for broadband ground-motion simulations. In particular, the variability in ground-motion predictions evaluated by linear, equivalent-linear, and nonlinear models is 

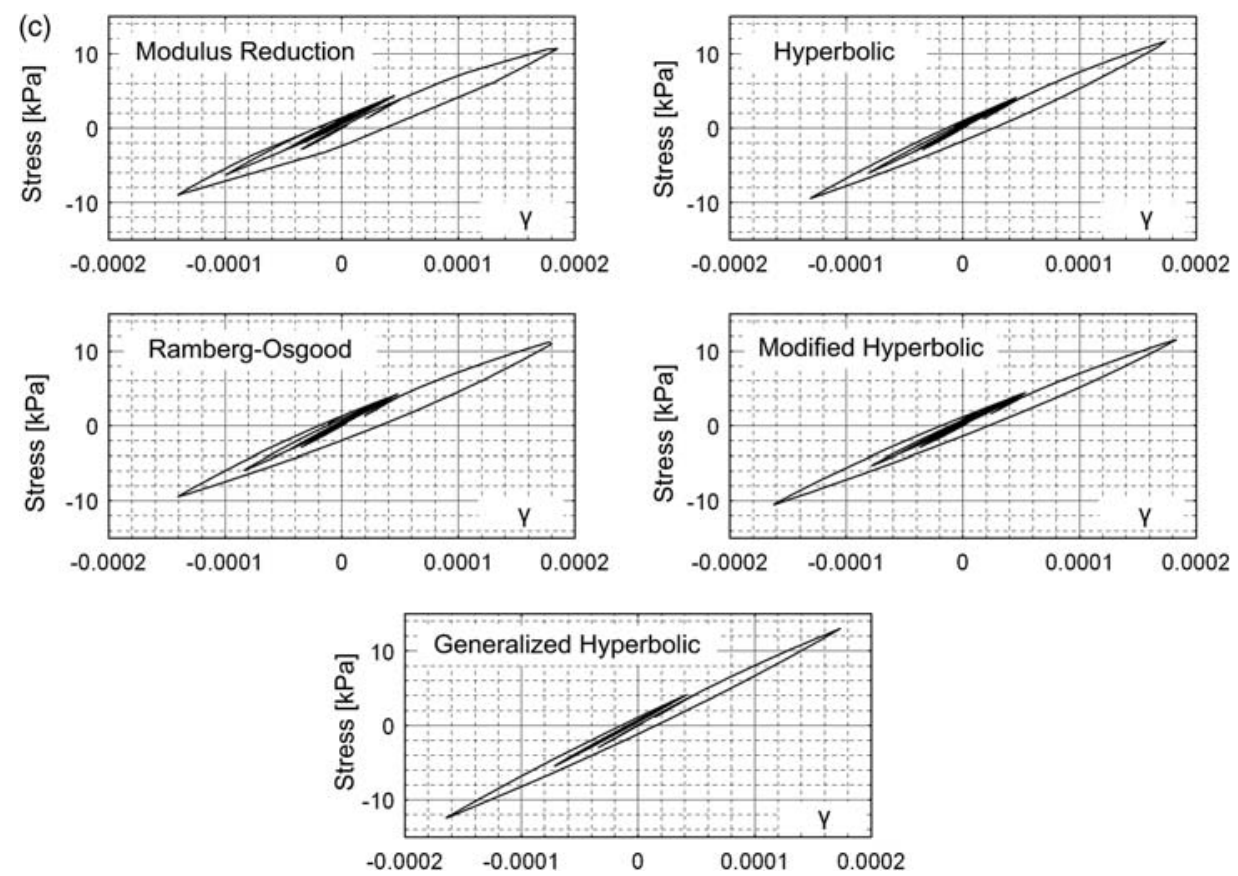

Figure 13. Continued.

used as proxy of the extent of nonlinear response of nearsurface soil profiles, and based on the estimates of relative modeling uncertainty, guidelines are developed to describe the conditions under which nonlinear models should be implemented in forward rupture-to-ground surface simulations, accompanied by suggestions on the optimal complexity of the models.

In accordance to the formulation of attenuation relations, site-response modeling uncertainty is initially evaluated by means of the coefficient of variance (COV) of site-spectral amplification predicted by the ensemble of methodologies as a function of the station distance from the ground surface projection of the fault $(d)$ and the mag-

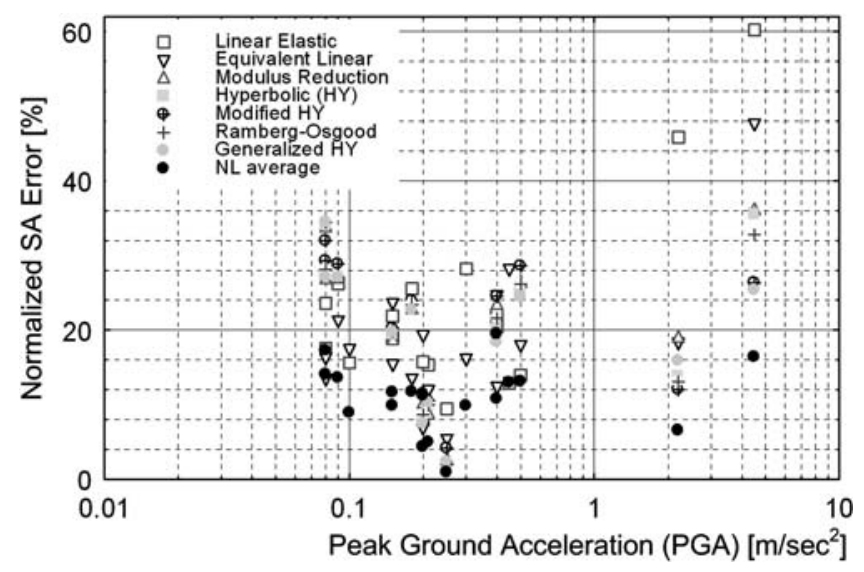

Figure 14. Cumulative spectral acceleration error in predicted response for the ensemble of approximate and incremental nonlinear algorithms investigated in this study. nitude $(M)$ of the simulated event. More specifically, the amplification factor predicted by the $j$ th site-response methodology at period $T_{i}$ is defined as

$$
A_{j}\left(T_{i}\right)=\left(A_{j}\right)_{i}=S A_{j}\left(T_{i}\right) / S A_{\mathrm{RO}}\left(T_{i}\right),
$$

where $S A_{j}\left(T_{i}\right)$ is the spectral acceleration on the ground surface and $S A_{\mathrm{RO}}\left(T_{i}\right)$ is the linear elastic spectral acceleration on the reference site conditions (referred to as NEHRP BC boundary). Successively, the coefficient of variation at period $T_{i},(\mathrm{COV})_{i}$ of the alternative methodologies at period $T_{i}$ is defined as

$$
(\mathrm{COV})_{i}=\sigma\left(A_{j}\right)_{i} / \mu\left(A_{j}\right)_{i}
$$

Finally, the overall COV is defined as the mean of COV across the response spectral period range $T_{i}=[0.04-2.0 \mathrm{sec}]$, namely,

$$
\mathrm{COV}=\mu(\mathrm{COV})_{i} .
$$

Figure 16 illustrates contour plots of the COV distribution for the three sites and two horizontal ground-motion components, which represents the variability in predicted amplitudes of PGA and SA at periods $T=0.3 \mathrm{sec}$ and $T=1 \mathrm{sec}$. The COV ranges from 0 to 0.5 , and large values of COV correspond to large intensity events $(M>6)$ at nearfield $(d<50 \mathrm{~km})$ stations. Nonetheless, regions of large PGA COV are also identified for $5<M<6$ and $d>50 \mathrm{~km}$ for all three site classes investigated (classes $C, D$, and $E$ ), which is an indication that the $M-d$ description of ground motion may not adequately describe the nonlinear- 
(a)
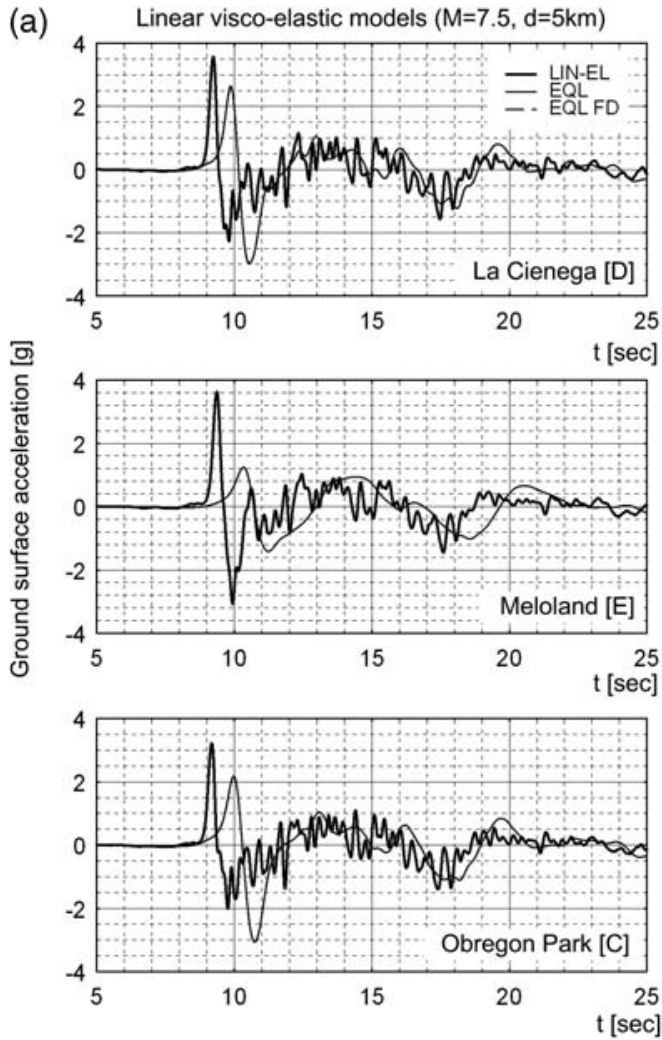
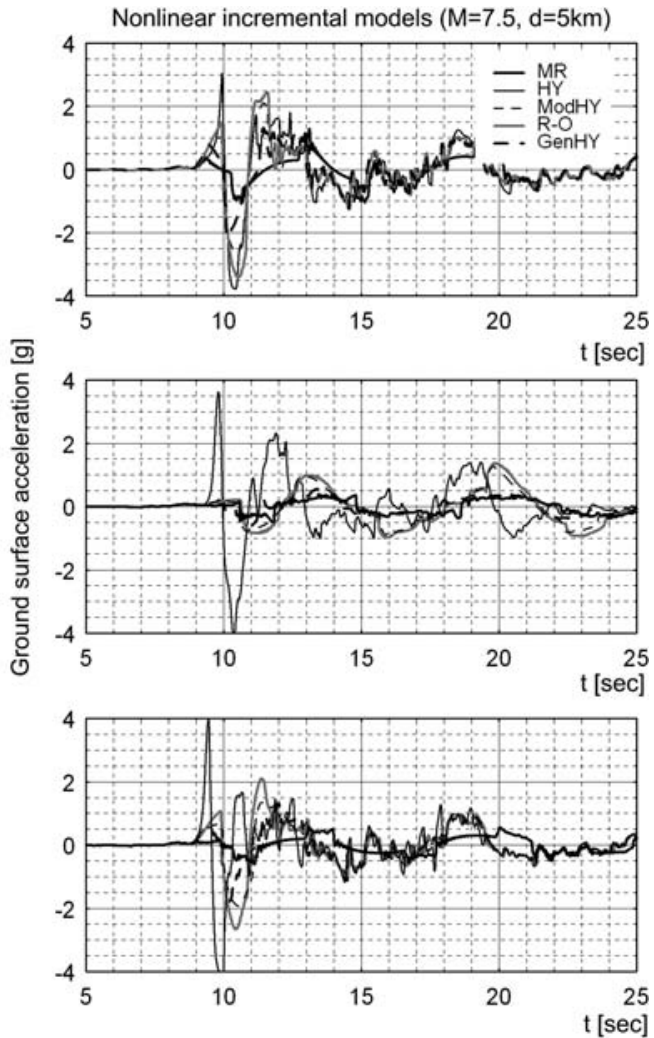

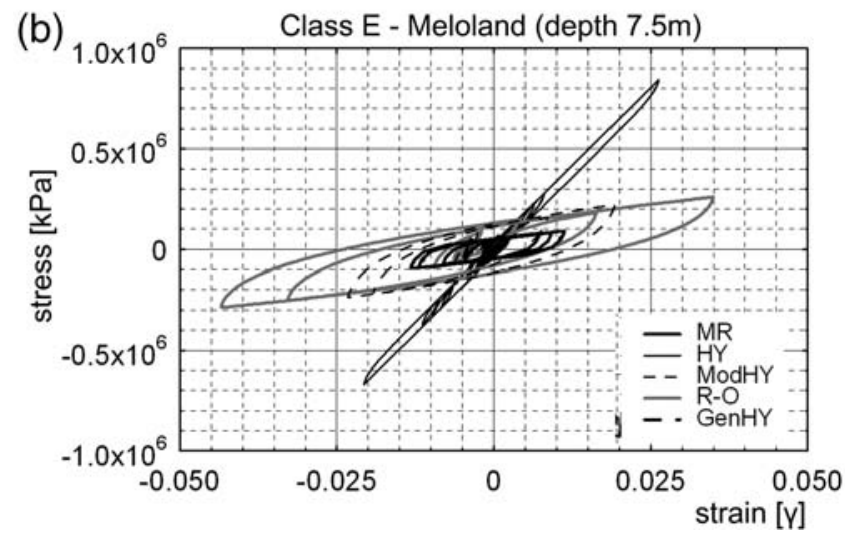

Figure 15. Surface synthetic ground-motion predictions by the ensemble of site-response models for the three profiles investigated during an $M 7.5$ event recorded at station s07 located at a distance $5 \mathrm{~km}$ from the fault (fault-normal component): (a) ground surface acceleration records and (b) predicted hysteresis loops by the ensemble of nonlinear models at a depth $7.5 \mathrm{~m}$ from ground surface for the profile at Meloland SMGA (LIN-EL: linear elastic, EQL: equivalent linear, EQL-FD: equivalent linear frequency dependent, MR: modulus reduction, HY: hyperbolic, ModHY: modified hyperbolic, GenHY: generalized hyperbolic and R-O: Ramberg-Osgood).

ity susceptibility of a soil profile, given the site class categorization. This in turn implies that the $M-d$ characterization of ground motion at a given site may not be used for the development of guidelines to describe the complexity of nonlinear model that should be employed for the computationally efficient prediction of site effects. Indeed, the nonlinearity susceptibility of a site is a function of both the site conditions and the incident ground-motion intensity and frequency content; while the former describes the strength of the material, the latter represents the amplitude of wave- lengths of the same order of magnitude as the soft layers of the profile that may potentially be driven to the nonlinear range. Therefore, a description based on the magnitude distance of the station and the site conditions is not adequate to describe the frequency content of the ground motion (Assimaki et al., 2008).

Based on wave propagation principles, an intensityfrequency criterion is next developed to describe the nonlinearity susceptibility of soil formations subjected to strong ground motion. The variability in predicted ground- 

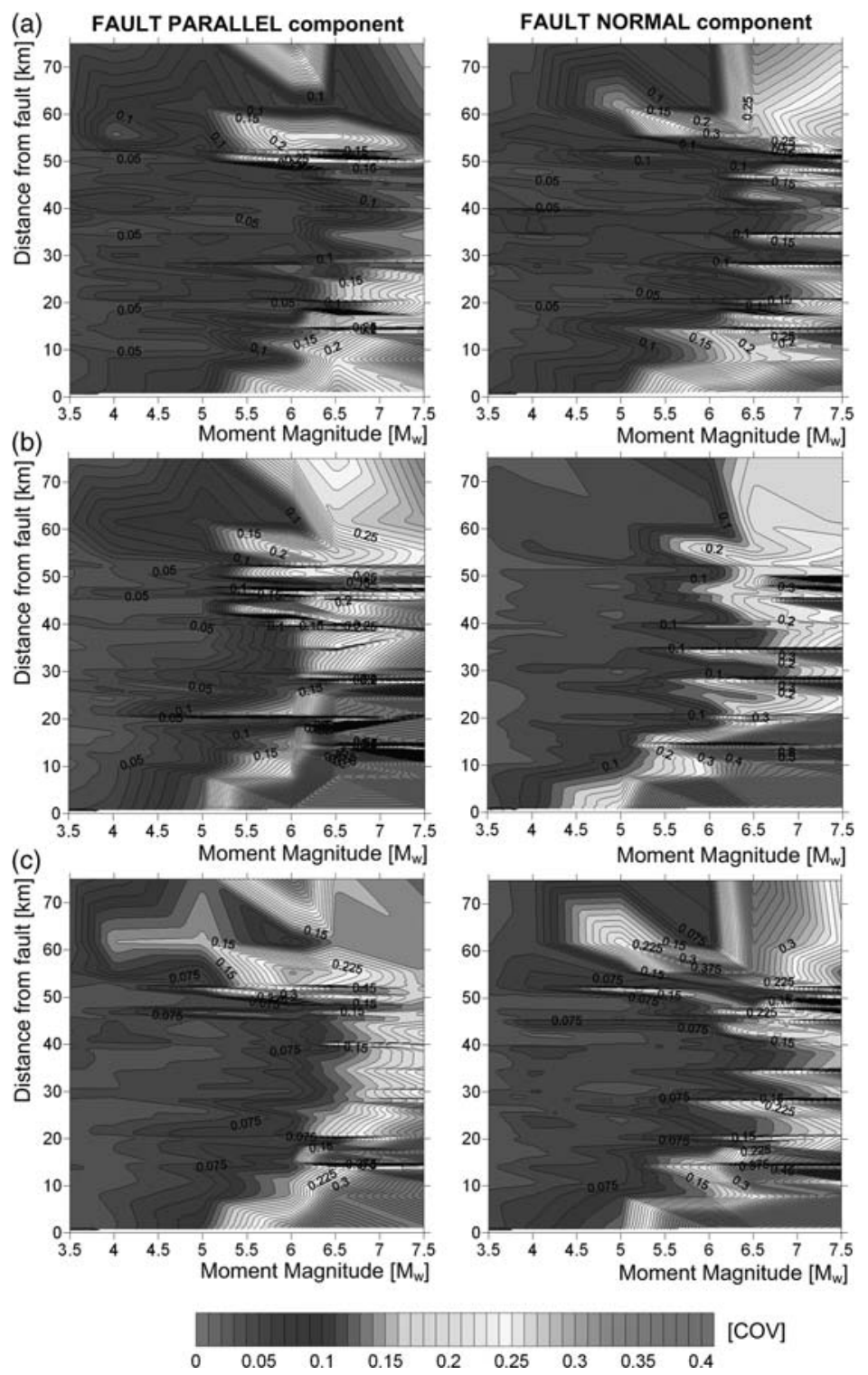

Figure 16. Average coefficient of variance (COV) of the predicted intensity measures (PGA and SA at $T=0.3 \mathrm{sec}$ and $T=1 \mathrm{sec}$ ) by the ensemble of site-response models, plotted as a function of distance of the station from the fault projection on ground surface and the moment of magnitude of the simulated events for the two components of horizontal motion (fault parallel and normal) and the three arrays studied: (a) La Cienega (class D), (b) Meloland (class E), and (c) Obregon Park (class $C$ ).

motion intensity measures (IMs) due to the site-response model (COV described previously) is here used as a proxy of the nonlinearity susceptibility, namely, the larger the deviation between linear elastic, equivalent-linear, and nonlinear predictions, the stronger the nonlinear effects manifesting in the near surface. In particular, the PGA on rock outcrop $\left(\mathrm{PGA}_{\mathrm{RO}}\right)$, namely, the acceleration predicted by the broadband ground-motion simulations on the ground surface of the BC boundary, is used to describe the intensity of incident ground motion.

Next, a frequency content index is introduced in the criterion to describe the frequency range where the incident waves possess energy and assess whether the excitation wavelengths can resonate with the near-surface soft layers of the profile. The frequency index is thereafter referred to as normalized central ground-motion frequency $\left(f_{N}\right)$ and corresponds to the ratio of the central frequency of the linear elastic profile transfer function $\left(f_{c, S}\right)$ to the central rock outcrop ground-motion frequency $\left(f_{c, \mathrm{RO}}\right)$. In each case, the central frequency is defined as the ratio of the second $\left(\lambda_{2}\right)$ to the first- $\left(\lambda_{1}\right)$ order spectral moments of the amplitude spectra as follows:

$$
f_{c}=\frac{\lambda_{2}}{\lambda_{1}}=\frac{\int f^{2} F S(f) d f}{\int f F S(f) d f}
$$

where $F S(f)$ is the smoothed Fourier amplitude spectrum of the rock outcrop ground motion or the amplitude spectrum 


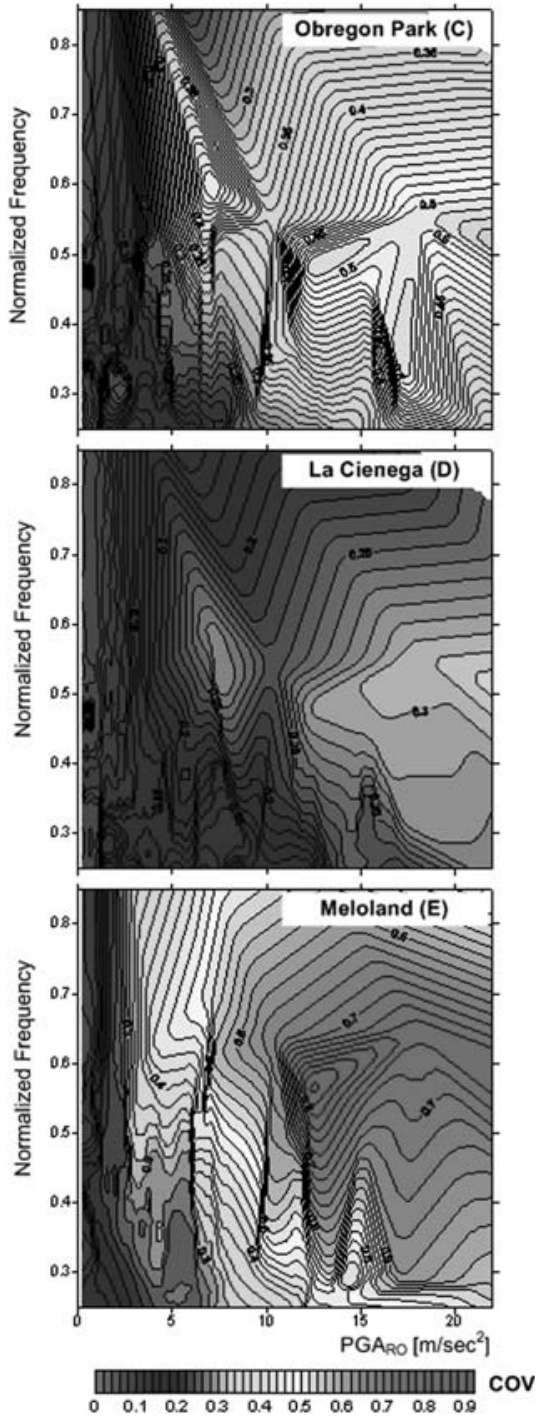

Figure 17. Contour maps of the average coefficient of variance of the predicted site-amplification spectrum (COV) for the alternative nonlinear models investigated in this study as a function of the peak ground acceleration (PGA) on rock outcrop and the mean frequency of the rock-outcrop motion normalized by the mean frequency of the theoretical site-transfer function at three sites representative of site classes $C$ (Obregon Park), $D$ (La Cienega), and $E$ (Meloland).

of the site-response transfer function; the resulting central frequencies are $f_{c, \text { RO }}$ or $f_{c, S}$ correspondingly. Welch's modified periodogram (Oppenheim and Schafer, 1999) was implemented for the smoothing of the corresponding spectra by means of a 10 -sec Parzen window with 2.5 -sec overlap.

Note that when $f_{N}=1$, the mean energy of the incident ground motion is carried by wavelengths on the same order of magnitude as the near-surface layers of the profile, and the seismic-motion amplification potential is maximized. Nonetheless, amplification of high intensity seismic waves is associated with nonlinear material response during which the average material stiffness in reduced, and the average mean nonlinear resonant frequencies are reduced in accordance. Therefore, high nonlinearity represented by high COV of the nonlinear models is anticipated for values of $f_{N}$ less than unity. An additional advantage of the amplitude-frequency representation of seismic motion relative to the resonant characteristics of the soil profile is the unified representation of fault-normal and fault-parallel motion components and near-field versus far-field pulses in the description of the anticipated extent of nonlinearity for the computationally efficient integration of site effects in ground-motion simulations.

In accordance with the intensity-frequency representation of nonlinearity susceptibility, Figure 17 plots the average COV contours (for $T=0-1.0 \mathrm{sec}$ ) as a function of $f_{N}$ and $\mathrm{PGA}_{\mathrm{RO}}$ for the three sites. As can be readily seen in Figure 17, the COV increases with increasing ground-motion intensity (here represented by the increasing $\mathrm{PGA}_{\mathrm{RO}}$ ) and is maximized for normalized central frequencies $f_{N}$ in the range [0.4-0.6]. As explained before, with increasing motion intensity, the nonlinear soil response in the near surface becomes more pronounced, which results in reduction of the shear-wave velocity. In turn, this averaged softening of the material reduces the site-resonant frequencies $\left(f_{c, S}\right)$, and because $\left(f_{c, \mathrm{RO}}\right)$ is constant, strong nonlinear phenomena correspond to $f_{N}<1$. The intensity-frequency regions that correspond to large values of COV imply large incompatibilities between the alternative site-response prediction methodologies, which in turn indicates that nonlinear analyses should be conducted to allow credible predictions of strong-motion site response.

Finally, Figure 18a,b plots the relative modeling error of the linear elastic and equivalent-linear site-response analyses correspondingly, using the average nonlinear spectral response as an estimate of the true nonlinear behavior based on the ground-motion error estimated in Figure 14, as follows:

$$
e_{S A}=\frac{1}{n} \sqrt{\sum_{i=1}^{n}\left[\frac{S A_{E}\left(T_{i}\right)-S A_{p}\left(T_{i}\right)}{S A_{E}\left(T_{i}\right)}\right]^{2}},
$$

where $S A_{E}$ and $S A_{p}$ are the estimated and predicted spectral acceleration values at period $T_{i}$, and $i=1 \ldots n$ is the number of points computed in the response spectrum.

As expected, the SA prediction error of the linear elastic site-amplification analysis correlates with the $\mathrm{COV}$ of siteresponse estimates: large $\mathrm{COV}$ indicates divergence of the nonlinear methodologies from the linear elastic simulations, which in turn is reflected on the increased modeling error in Figure 18a. Similar results are evaluated for the equivalentlinear method, which are shown in Figure 18b. As expected, relative error values are lower than the linear elastic case for the same $\mathrm{PGA}_{\mathrm{RO}}$ intensity, while the error from both site-response methodologies is maximized in the same frequency-index region. As an example, for the case of Meloland that represents the softer of site conditions investigated (class $E$ ), a $50 \%$ relative error is observed for $\mathrm{PGA}_{\mathrm{RO}}>0.2 \mathrm{~g}$ for $f_{N} \sim 0.5$ in the linear elastic site-response estimation, 

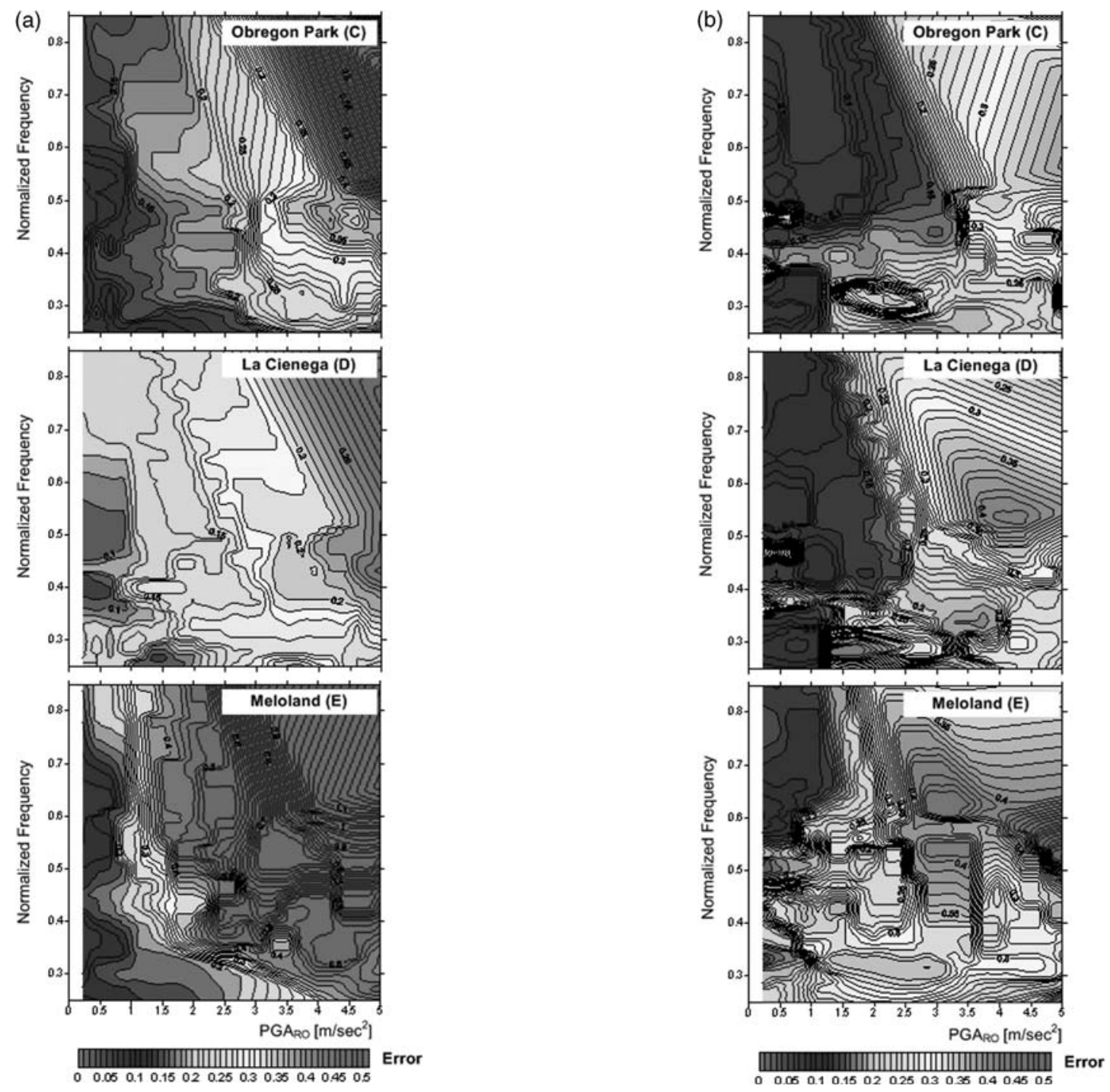

Figure 18. (a) Contour maps of the normalized error of linear elastic site-amplification spectrum for PGA $<0.5 g$, defined as the divergence of the predicted site response from the average predicted amplification by the ensemble of nonlinear models, as a function of the peak ground acceleration (PGA) on rock outcrop and the central frequency of the theoretical site transfer function at three sites representative of site classes $C$ (Obregon Park), $D$ (La Cienega), and $E$ (Meloland) normalized by the central frequency of the rock-outcrop motion. (b) Contour maps of the normalized error of equivalent-linear site-amplification spectrum for PGA $<0.5 \mathrm{~g}$, defined as the divergence of the synthetic site response from the average predicted amplification by the ensemble of nonlinear models, as a function of the PGA on rock outcrop and the mean frequency of the rock-outcrop motion normalized by the mean frequency of the theoretical site-transfer function at three sites representative of site classes $C$ (Obregon Park), $D$ (La Cienega), and $E$ (Meloland).

while the same error is observed for $\mathrm{PGA}_{\mathrm{RO}}>0.4 g$ and $f_{N} \sim$ 0.5 in the equivalent-linear site-response estimation.

Results from this section show that the intensityfrequency representation of ground motion may be implemented as an efficient criterion to define the nonlinearity susceptibility of soil formations given a ground-motion time history, accounting simultaneously for the magnitudedistance-orientation characteristics of the incident seismic motion and the site stiffness. Successively, the level of acceptable error threshold for the site-response predictions needs to be defined based on the target degree of design sophistication at a given site to allow the selection of the optimal site-response methodology in terms of computational effort. Undoubtedly, the development of such a set of criteria and associated suggested methodologies should be based on a statistically significant number of sites and observations, and this work should be interpreted as a framework for similar future analyses.

\section{Site-Amplification Factors in Seismic Design Codes and Attenuation Relations}

Beyond the implementation of nonlinear methods in simulating the site-specific ground response in broadband 
ground-motion models for deterministic scenarios, selection of the methodology for prediction of site effects also affects the development of amplification factors for implementation in synthetic attenuation relations. In this section, this variability is investigated by computing the spectral amplification at different periods for the alternative site-response methodologies at the three sites in the LA basin, and comparing results to the values suggested by parts 1 and 2 of BSSC (2001) and to recently published amplification factors for tectonically active regions (Choi and Stewart, 2005) for the corresponding site conditions (classes $C, D$, and $E$ ).

Figure $19 \mathrm{a}-\mathrm{c}$ depicts the variation of site amplification relative to the reference site (NEHRP BC boundary) PGA, evaluated by means of the linear elastic, equivalent-linear, and average nonlinear models for the Obregon Park (class

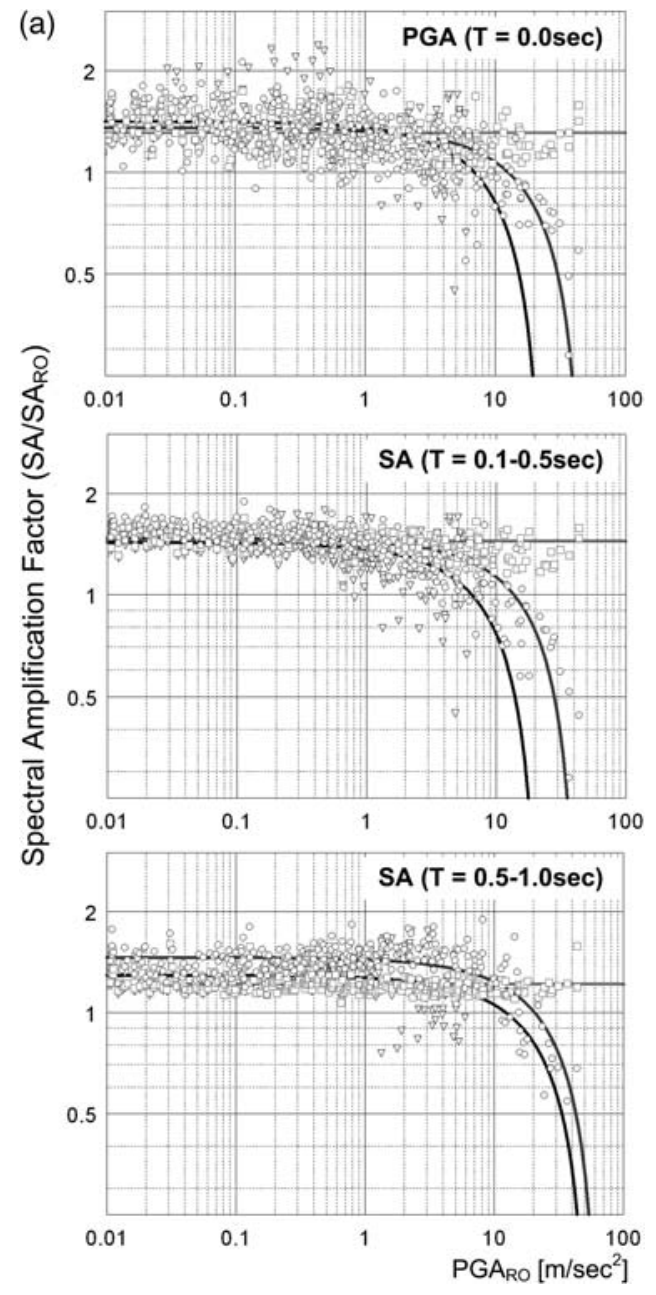

$C$ ), La Cienega (class $D$ ), and Meloland (class $E$ ) sites, respectively. As can be readily seen, the divergence of the predicted site-amplification factors among the alternative models increases proportionally to the $\mathrm{PGA}_{\mathrm{RO}}$, and the ground-motion intensity where nonlinearity manifests and the predictions start to deviate from each other is proportional to the stiffness of the profile. In particular, the alternative site-amplification estimates deviate significantly for $\mathrm{PGA}_{\mathrm{RO}}>0.4 g$ for class $C$, for $\mathrm{PGA}_{\mathrm{RO}}>0.3 g$ for class $D$, and for $\mathrm{PGA}_{\mathrm{RO}}>0.1 \mathrm{~g}$ for class $E$ site conditions. Similar conclusions are drawn for the effectiveness of the equivalentlinear operator to approximate the nonlinear site response, namely, as the site conditions become softer, the two estimates of strong-motion ground surface response are shown to deviate for lower intensity measures. It should also be

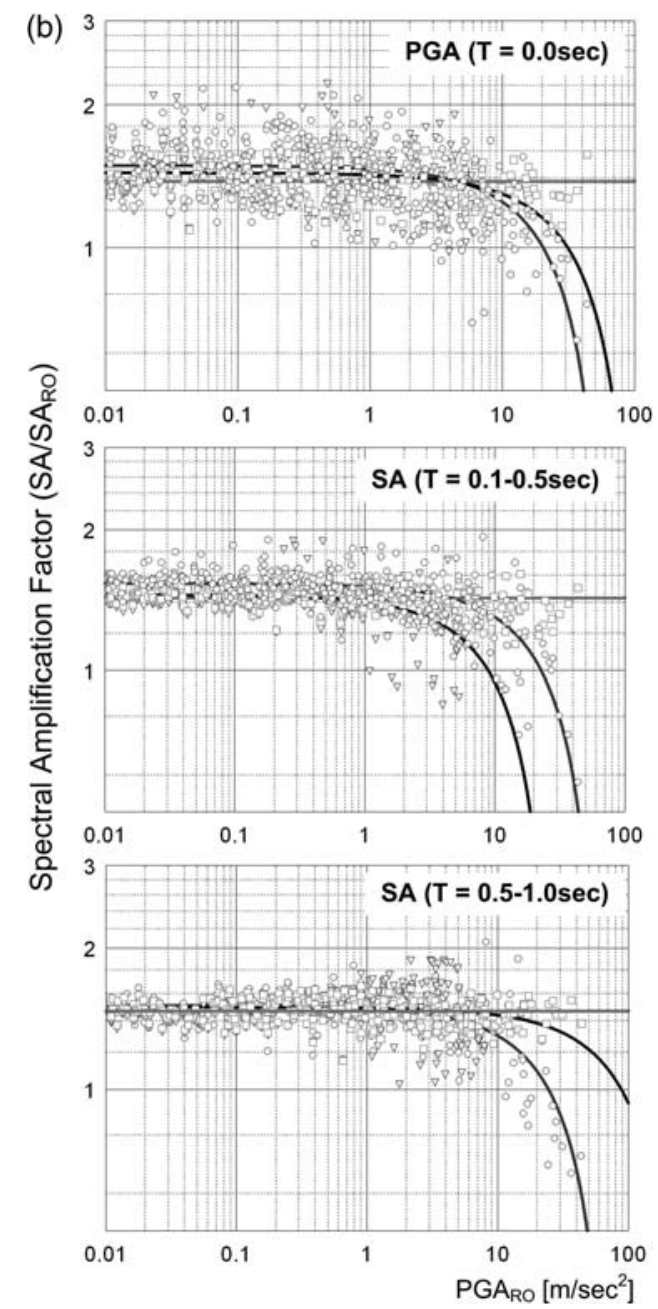

Figure 19. Ground surface to BC boundary $\left(V_{s 30}=760 \mathrm{~m} / \mathrm{sec}\right)$ site-amplification factors for the Obregon Park site conditions (class $C$ ) for the alternative site-response estimators evaluated in this study: (squares) linear elastic wave propagation, (triangles) equivalent-linear iterative analysis, and (circles) nonlinear average site response of the ensemble of incremental time-domain models investigated. (b) Ground surface to BC boundary $\left(V_{s 30}=760 \mathrm{~m} / \mathrm{sec}\right)$ site-amplification factors for the La Cienega site conditions (class $\left.D\right)$ for the alternative siteresponse estimators evaluated in this study: (squares) linear elastic wave propagation, (triangles) equivalent-linear iterative analysis, and (circles) nonlinear average site response of the ensemble of incremental time-domain models investigated. (c) Ground surface to BC boundary $\left(V_{s 30}=760 \mathrm{~m} / \mathrm{sec}\right)$ site-amplification factors for the Meloland site conditions (class $E$ ) for the alternative site-response estimators evaluated in this study: (squares) linear elastic wave propagation, (triangles) equivalent-linear iterative analysis, and (circles) nonlinear average site response of the ensemble of incremental time-domain models investigated.

(Continued) 


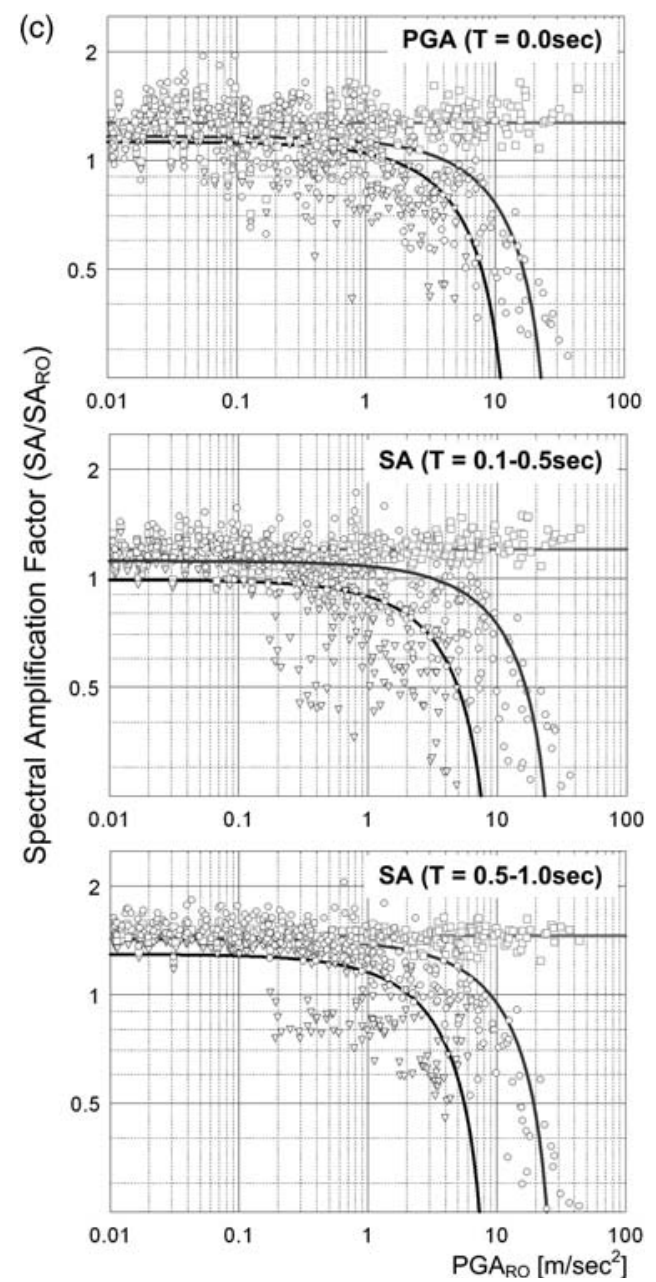

Figure 19. Continued.

noted that convergence of the equivalent-linear operator was limited to amplitudes of $\mathrm{PGA}_{\mathrm{RO}}>0.75 \mathrm{~g}$, and results for stronger ground-motion simulations are not included here.

Successively, Figure 20 compares currently employed low- and midperiod site-amplification factors for class $C$, $D$, and $E$ site conditions to the average nonlinear ground surface site-response predictions in this study that were selected as the best estimate of the true site response at the three sites based on observations. In particular, results from this study are compared to:

1. Currently employed NEHRP site factors, which are based on both empirical data and ground response analyses conducted by Dobry et al. (2000). The empirical studies had been performed by Borcherdt (1994), Borcherdt and Glassmoyer (1994), and Joyner et al. (1994) using strong-motion data recorded in the San Francisco Bay Area during the 1989 Loma Prieta earthquake, and they have led to amplification factors $\left(F_{a}\right.$ and $\left.F_{v}\right)$ applicable for relatively weak levels of shaking (peak horizontal acceleration for reference site conditions and peak hori- zontal acceleration at the reference site on the order of $\approx 0.1 \mathrm{~g}$ ). These amplification factors were derived using a so-called reference site approach, in which the amplification is defined as the ratio of Fourier spectral ordinates of motions recorded on soil to those recorded on nearby reference rock sites. In particular, the specific factors given in the provisions are $F_{a}$, which is defined over a low-period range $(0.1-0.5 \mathrm{sec})$, and $F_{v}$, which is defined over a midperiod range $(0.4-2.0 \mathrm{sec})$. The ground-motion parameters for the reference site condition that are used in conjunction with site factors are $T=$ $0.2 \mathrm{sec}$ spectral acceleration for $F_{a}$ (denoted $S_{S}$ ) and spectral acceleration at $T=1.0 \mathrm{sec}$ for $F_{v}$ (denoted $S_{l}$ ).

2. The amplification factors of Choi and Stewart (2005), which were derived based on 1828 recordings from 154 earthquakes, using recordings from worldwide shallow crustal earthquakes near active plate margins and excluding subduction and interplate events. In contrast to published studies by Boore and Atkinson (2006), Chiou and Youngs (2006) (http://peer.berkeley.edu/prod-ucts/ nga_project.html), and Campbell and Bozorgnia (2007), Choi and Stewart (2005) derived their factors as continuous functions of both $\mathrm{PGA}_{\mathrm{RO}}$ and $V_{s 30}$, and they converted the reference site conditions to a consistent BC-boundary reference profile, which eliminates inconsistencies in the description of the reference soil profile as a source of divergence in the compared siteamplification factors illustrated in Figure 20.

3. The generic site coefficients derived by Park and Hashash (2005), from the probabilistic surface uniform hazard response spectra, published in a format similar to NEHRP site coefficients with an added dimension of the embayment deposits thickness to characterize the influence of thick deposits of the upper Mississippi embayment. Park and Hashash (2005) developed an integrated probabilistic seismic-hazard analysis procedure that incorporated nonlinear (PSHA-NL) site effects, following the methodology of the 2002 U.S. Geological Survey (USGS) hazard maps to generate a compatible set of ground-motion records. In PSHA-NL, site effects were directly accounted for by propagating the motions using nonlinear and equivalent-linear site-response analyses. From the series of coefficients, Figure 20 depicts the ones corresponding to $30-\mathrm{m}$ soil profiles that were shown to compare well with the NEHRP site coefficients, and they were developed for two generic shear-wave profiles of the Mississippi embayment (Romero, 2001), referred to as Uplands and Lowlands.

As can be readily seen for class $C$ site conditions, both short- $(T=0.2 \mathrm{sec})$ and midperiod $(T=0.1 \mathrm{sec})$ currently employed amplification factors are in excellent agreement with the synthetic database of site-response analyses developed in this study. Similar results are observed for the class $D$ soil profile under investigation, with the exception of the divergence depicted between published relationships and syn- 

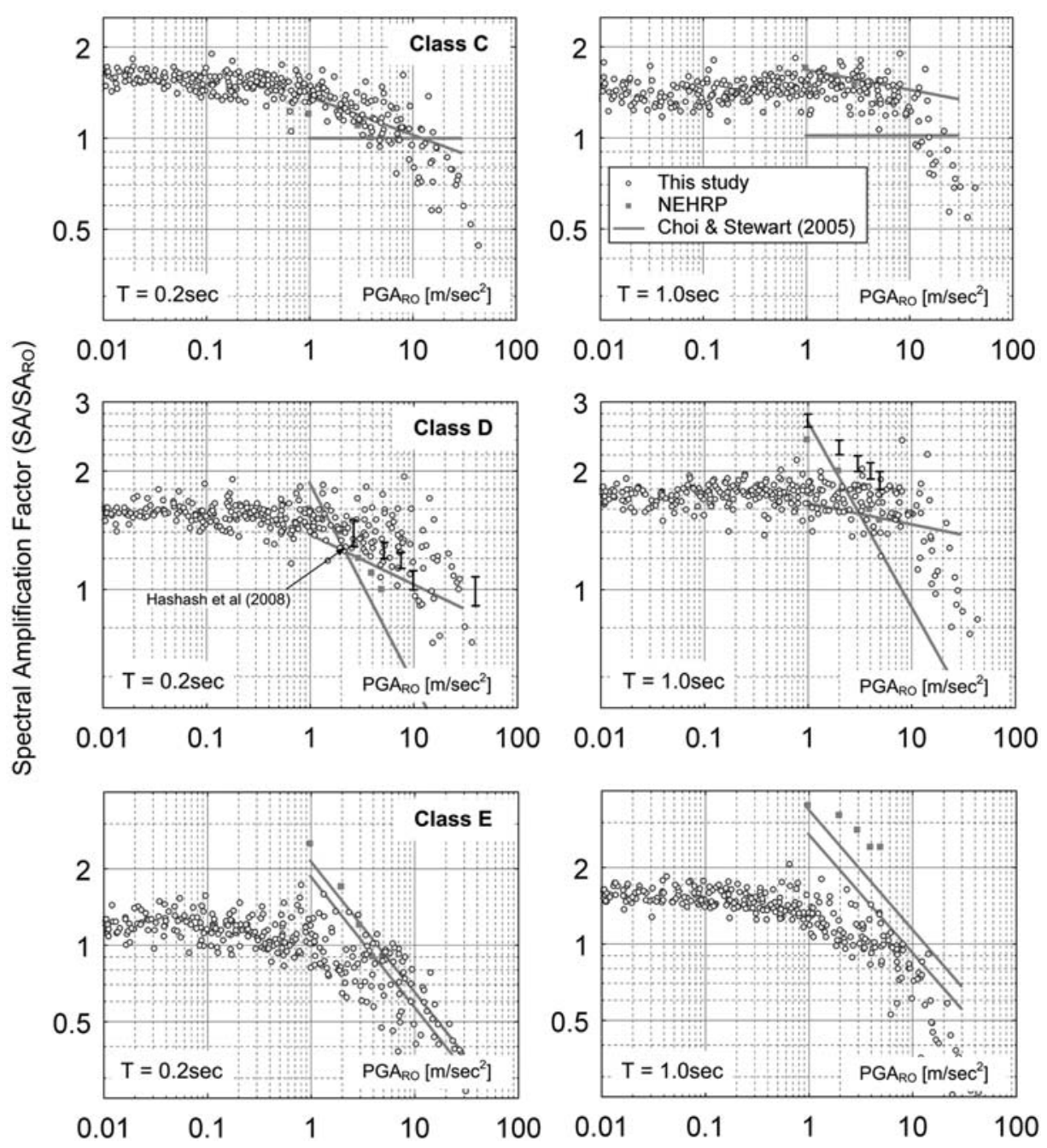

Figure 20. Comparison of nonlinear site-amplification factors averaged over the ensemble of incremental time-domain models to the currently employed NEHRP site-amplification factors for class $C, D$, and $E$ site conditions, as well as to the recently published Choi and Stewart (2005) site-amplification factors evaluated consistently for the BC-boundary reference site conditions $\left(V_{s 30}=760 \mathrm{~m} / \mathrm{sec}\right)$. Sitespecific amplification factors developed by Park and Hashash (2005) for the Mississippi embayment corresponding to a 30-m-depth soil profile and class $D$ site conditions are also depicted for comparison.

thetic amplification factors in the low-amplitude $\mathrm{PGA}_{\mathrm{RO}}$ region of the midperiod $(T=1.0 \mathrm{sec})$ components.

On the other hand, strong deviation of the synthetic from the currently employed amplification factors is observed for the class $E$ site (i.e., Meloland), especially in the midperiod range $(T=1.0 \mathrm{sec})$. Both the NEHRP and Choi and Stewart (2005) site-amplification factors are shown to overestimate the amplification anticipated (or underestimate the extent of nonlinearity exerted by the soil profile) by a factor on the order of 1.5, while the effect is more pronounced in the midperiod range of the spectrum $(T=1.0 \mathrm{sec})$. This indicates that currently employed amplification factors may be implemented to predict the level of amplification for class $C$ and $D$ site conditions, while site-specific simulations should be employed for strong ground-motion analyses at class $E$ sites, and for this case in particular, incremental nonlinear analyses for levels of $\mathrm{PGA}_{\mathrm{RO}}>0.2 \mathrm{~g}$.

\section{Conclusions}

The effects of near-surface soil stratigraphy on the amplitude and frequency content of ground motion are accounted for in most modern U.S. seismic design codes for building structures as a function of the soil conditions prevailing in the area of interest. Nonetheless, currently employed site-classification criteria do not adequately describe the nonlinearity susceptibility of soil formations, a fact that prohibits the development of standardized procedures for the computationally efficient integration of nonlinear ground response analyses in broadband ground-motion simulations. In 
turn, the lack of a unified methodology for nonlinear siteresponse analyses affects both the prediction accuracy of sitespecific ground-motion intensity measures and the evaluation of site-amplification factors when broadband simulations are used for the development of hybrid attenuation relations.

In this article, a set of criteria has been introduced to quantify the nonlinearity susceptibility of soil profiles based on the site conditions and incident ground-motion characteristics, and we implement them to identify the least complex ground response prediction methodology required for the simulation of nonlinear site effects at three sites in the Los Angeles basin. The criteria are developed on the basis of a comprehensive nonlinear site-response modeling uncertainty analysis, which includes both detailed soil profile descriptions and statistical adequacy of ground-motion time histories. Approximate and incremental nonlinear models are implemented, and the limited site-response observations are initially compared to the ensemble site-response estimates. Evaluating the error between predictions and observations for the ensemble of ground motions recorded at the three sites shows that the average nonlinear response spectrum yields the closest representation of the observed response. The error of the average nonlinear predictions is on the order of $15 \%-20 \%$ and practically independent of the ground-motion intensity, while as expected, the prediction error of the linear elastic operator is proportional to the amplitude of PGA. The variability in predicted motions via the nonlinear models, however, is shown to increase with the motion intensity, which is attributed to the differences in the idealizations of the stress-strain material response that become more pronounced with increasing strain amplitude, namely, increasing motion intensity.

Next, a suite of synthetic ground motions for rupture scenarios of weak, medium, and large magnitude events (M 3.5-7.5) is generated, parametric studies are conducted for each fixed magnitude scenario by varying the source-tosite distance, and the variability introduced in ground-motion predictions due to the selection of the nonlinear model is quantified. In particular, the alternative site-response models are used to predict the synthetic ground surface motion and to evaluate the relative uncertainty introduced by the model selection based on comparison of the predictions with the best estimate of true site response, namely, the average nonlinear ground-motion spectrum. The variability in groundmotion predictions evaluated by linear, equivalent-linear, and nonlinear models is used to indicate the extent of nonlinearity exerted by the soil formations in the near surface.

Results of the modeling uncertainty assessment are used to quantify the nonlinearity susceptibility of the three sites, and they subsequently suggest the optimal prediction methodology of nonlinear site effects for broadband groundmotion simulations. For this purpose, a frequency index is developed to describe the frequency content of incident ground motion relative to the resonant frequencies of the soil profile, namely, the frequency range where the incident waves possess energy and assess whether the excitation wavelengths can resonate with the near-surface soft layers of the profile. This frequency index is used in conjunction with the rock-outcrop acceleration peak amplitude $\left(\mathrm{PGA}_{\mathrm{RO}}\right)$ to identify the site conditions and ground-motion characteristics where incremental nonlinear analyses should be employed in lieu of approximate methodologies. An advantage of the amplitude-frequency representation of seismic motion relative to the resonant characteristics of the soil profile is the unified representation of fault-normal and fault-parallel motion components and near-field versus far-field pulses in the description of the anticipated extent of nonlinearity for the computationally efficient integration of site effects in ground-motion simulations.

Comparing the amplitude-frequency regions of large variability of predicted intensity measures at the three sites, it is shown that the proposed representation of ground motion may be implemented to describe the nonlinearity susceptibility of soil formations in broadband simulations while eliminating the drawbacks of subjective description of site conditions in the currently employed site-classification system. Successively, given a quantitative measure of site proneness to nonlinearity and the level of acceptable error threshold for the site-response predictions based on the target degree of design sophistication, the amplitude-frequency criteria will allow the selection of the computationally optimal site-response methodology.

The synthetic ground-motion predictions are finally used for the development of site-amplification factors for the alternative site-response methodologies, and results are compared to published site factors of attenuation relations. For the site conditions investigated, currently established amplification factors compare well with synthetic simulations for class $C$ and $D$ site conditions, while long-period amplification factors are overestimated by a factor of 1.5 at the class $E$ site, where site-specific nonlinear analyses are shown to be required for levels of $\mathrm{PGA}_{\mathrm{RO}}>0.2 g$.

Selection of the appropriate methodology for prediction of soil nonlinearity in strong ground motion is based on the anticipated strain amplitude, and while equivalentlinear formulations have been shown to produce reasonable results for low-strain amplitudes, nonlinear methods are necessary to capture phenomena such as irreversible deformations and pore pressure coupling. The accuracy of nonlinear site-response analyses, however, depends on the constitutive model used, and elaborate constitutive models require numerous parameters that must be determined through lab tests and/or field tests; in turn, this additional effort involved to develop the required parameters often limits their frequency of use. We have introduced a set of criteria to describe nonlinearity susceptibility of three profiles in the Los Angeles basin and implemented them to identify the nonlinear methodology required for the accurate prediction of nonlinear effects, yet, undoubtedly, the development of such a set of criteria and associated suggested methodologies should be based on a statistically significant number of sites and observations. To that end, the procedure described in this 
article should be viewed as a framework for similar future analyses, and extension of this study to a large sample of site conditions and regional hazard-consistent ground-motion scenarios shall lead to the establishment of guidelines for the integration of credible and computationally efficient nonlinear site-response analyses in broadband seismological ground-motion models.

\section{Data and Resources}

Seismograms used in this study were collected from the following sources: (i) COSMOS Virtual Data Center (http://db.cosmos-eq.org/scripts/default.plx), (ii) Southern California Earthquake Data Center (SCEDC) (http://www .data.scec.org/), and (iii) Pacific Earthquake Engineering Research (PEER) Project 2G02 Benchmarking of Nonlinear Geotechnical Ground Response Analysis Procedures (http://cee.ea.ucla.edu/faculty/CalibrationSites/ Webpage/main.htm). Suspension logging tests and resonant column/torsional shear laboratory experimental data on the nonlinear soil response to transient loading were obtained from the Resolution of Site-Response Issues from the Northridge Earthquake web site (http://gees.usc.edu/ROSRINE/) as well as from personal communication with Dr. Jamison H. Steidl, Institute for Crustal Studies, University of California, Santa Barbara, CA 93106.

\section{Acknowledgments}

This research was supported by the Southern California Earthquake Center (SCEC). SCEC is funded by the National Science Foundation (NSF) Cooperative Agreement Number EAR-0106924 and the U.S. Geological Survey (USGS) Cooperative Agreement Number 02HQAG0008. The SCEC contribution number for this article is 1119 . The authors would also like to acknowledge the contribution of two anonymous reviewers whose editorial and conceptual comments significantly contributed to the preparation of the final version of this manuscript.

\section{References}

Aguirre, J., and K. Irikura (1997). Nonlinearity, liquefaction, and velocity variation of soft soil layers in Port Island, Kobe, during the HyogokenNanbu earthquake, Bull. Seismol. Soc. Am. 87, 1244-1258.

Assimaki, D., and E. Kausel (2002). An equivalent linear algorithm with frequency- and pressure-dependent moduli and damping for the seismic analysis of deep sites, Soil Dyn. Earthquake Eng. 22, 959-965.

Assimaki, D., and J. Steidl (2007). Inverse analysis of weak and strong motion downhole array data from the $M_{\mathrm{w}} 7.0$ Sanriku-Minami earthquake, Soil Dyn. Earthquake Eng. 27, no. 1, 73-92.

Assimaki, D., J. H. Steidl, and P. C. Liu (2006). Attenuation and velocity structure for site response analyses via downhole seismogram inversion, Pure Appl. Geophys. 163, no. 1, 81-118.

Assimaki, D., W. Li, J. H. Steidl, and K. Tsuda (2008). Site amplification and attenuation via downhole array seismogram inversion: a comparative study of the 2003 Miyagi-Oki aftershock sequence, Bull. Seismol. Soc. Am. 98, 301-330.

Bao, H., J. Bielak, O. Ghattas, L. F. Kallivokas, D. R. O'Hallaron, J. R. Shewchuk, and J. Xu (1998). Large-scale simulation of elastic wave propagation in heterogeneous media on parallel computers, Comput. Methods Appl. Mech. Eng. 152, 85-102.
Bardet, J. P., and T. Tobita (2001). Nonlinear Earthquake Site Response Analysis (NERA): User's Manual, University of Southern California, Los Angeles, California.

Berrill, J. B. (1977). Site effects during the San Fernando, California, earthquake, in Proceedings of the Sixth World Conference on Earthquake Engineering, New Delhi, India, 432-438.

Bonilla, L. F. (2001). NOAH: User's Manual, Institute for Crustal Studies, University of California, Santa Barbara, 38 pp.

Bonilla, L. F., R. J. Archeleta, and D. Lavellee (2004). Hysteretic and dilatant behavior of cohesionless soils and their effects on nonlinear site response: field data observations and modeling, Bull. Seismol. Soc. Am. 95, 2373-2395.

Boore, D. M., and G. M. Atkinson (2006). Boore-Atkinson NGA ground motion relations for the geometric mean horizontal component of peak and spectral ground motion parameters, PEER Report to the PEERLifelines Next Generation (NGA) Project, available from http://peer .berkeley.edu/products/Boore-Atkinson-NGA.html (report date: May 2007; revised 27 October 2006) (last accessed August 2008).

Boore, D. M., and W. B. Joyner (1997). Site amplification for generic rock sites, Bull. Seismol. Soc. Am. 87, 327-341.

Borcherdt, R. D. (1994). Estimates of site-dependent response spectra for design (methodology and justification), Earthq. Spectra 10, no. 4, 617-653.

Borcherdt, R. D. (1970). Effects of local geology on ground motion near San Francisco Bay, Bull. Seismol. Soc. Am. 60, 29-61.

Borcherdt, R. D., and J. F. Gibbs (1976). Effects of local geologic conditions in the San Francisco Bay region on ground motions and the intensities of the 1906 earthquake, Bull. Seismol. Soc. Am. 66, 467-500.

Borcherdt, R. D., and G. Glassmoyer (1994). Influences of local geology on strong and weak ground motions recorded in the San Francisco Bay region and their implications for site-specific building-code provisions, in The Loma Prieta California Earthquake of October 17, 1989Strong Ground Motion, U.S. Geol. Surv. Profess. Pap. 1551-A, A77-A108.

Building Seismic Safety Council (BSSC) (2001). NEHRP Recommended Provisions for Seismic Regulations for New Buildings and Other Structures, Part 1 - Provisions and Part 2 - Commentary, Reports No. FEMA-368 and FEMA-369, prepared by the Building Seismic Safety Council for the Federal Emergency Management Agency, Washington, D.C.

Campbell, K. W., and Y. Bozorgnia (2007). Campbell-Bozorgnia NGA ground motion relations for the geometric mean horizontal component of peak and spectral ground motion parameters, PEER Report to the PEER-Lifelines Next Generation (NGA) Project, available from http:// peer.berkeley.edu/products/Campbell-Bozorgnia_NGA.html (last accessed August 2008).

Carcione, J. M., D. Kosloff, and R. Kosloff (1988). Wave propagation in a linear viscoacoustic medium, Geophys. J. R. Astr. Soc. 93, 393-407.

Chin, B., and K. Aki (1991). Simultaneous study of the source, path, and site effects on strong ground motion during the 1989 Loma Prieta earthquake: a preliminary result on pervasive nonlinear site effects, Bull. Seismol. Soc. Am. 81, 1859-1884.

Chiou, B., and R. Youngs (2006). Chiou and Youngs PEER-NGA empirical ground motion model for the average horizontal component of peak acceleration and pseudo-spectral acceleration for spectral periods of 0.01 to 10 seconds, PEER Report to the PEER-Lifelines Next Generation (NGA) Project, available from http://peer.berkeley.edu/ products/Chiou_Youngs_NGA_2006.html (revised 14 June 2006) (last accessed August 2008).

Choi, Y., and J. P. Stewart (2005). Nonlinear site amplification as function of $30 \mathrm{~m}$ shear wave velocity, Earthq. Spectra 21, no. 1, 1-30.

Chopra, A. K. (2000). Dynamics of Structures: Theory and Applications to Earthquake Engineering, Second Ed., Prentice Hall, New York.

Cramer, C. H. (2006). Quantifying the uncertainty in site amplification modeling and its effects on site-specific seismic-hazard estimation in the upper Mississippi embayment and adjacent areas, Bull. Seismol. Soc. Am. 96 no. 6, 2008-2020. 
Cramer, C. H., J. S. Gomberg, E. S. Schweig, B. A. Waldron, and K. Tucker (2004). Memphis, Shelby County, Tennessee, seismic hazard maps, U.S. Geol. Surv. Open-File Rept. 04-1294, 41 pp.

Darragh, R. B., and A. F. Shakal (1991). The site response of two rock and soil station pairs to strong and weak ground motion, Bull. Seismol. Soc. Am. 81, no. 5 1885-1899.

Day, S. M., and J. R. Minster (1984). Numerical simulation of attenuated wavefields using a Pade approximant method, Geophys. J. R. Astr. Soc. 78, 105-118.

Dobry, R., R. D. Borcherdt, C. B. Crouse, I. M. Idriss, W. B. Joyner, G. R. Martin, M. S. Power, E. E. Rinne, and R. B. Seed (2000). New site coefficients and site classification system used in recent building seismic code provisions, Earthq. Spectra 16, no. 1, 41-67.

Drnevich, V. P., J. R. Hall Jr, and F. E. Richart Jr (1966). Large amplitude vibration effects on the shear modulus of sand, University of Michigan Report to Waterways Experiment Station, Corps of Engineers, U.S. Army, Contract DA-22-079-eng-340.

Duke, C. M., and A. K. Mal (1978). Site and source effects on earthquake ground motion, University of California, Los Angeles, Engineering Report No. 7890.

Duncan, J. M., and C.-Y. Chang (1970). Nonlinear analysis of stress and strain in soils, J. Soil Mech. Found. Div. 96, no. SM5, 1629-1653.

Earthquake Engineering Research Institute (2000). 1999 Kocaeli, Turkey, Earthquake Reconnaissance Report, in Earthq. Spectra, Supplement A to Vol. 16, December 2000.

Elgamal, A., M. Zeghal, and E. Parra (1995). Identification and modeling of earthquake ground response, in First International Conference on Earthquake Geotechnical Engineering, Tokyo, Japan, Vol. 3, 1369-1406.

Emmerich, H., and M. Korn (1987). Incorporation of attenuation into time-domain computations of seismic wave fields, Geophysics $\mathbf{5 2}$, $1252-1264$

Faccioli, E. E., V. Santayo, and J. L. Leone (1973). Microzonation criteria and seismic response studies for the city of Managua, in Proceedings of the Earthquake Engineering Research Distribution Conference on the Managua, Nicaragua, Earthquake of December 23, 1972, Vol. 1, 271-291.

Hardin, B. O., and V. P. Drnevich (1972a). Shear modulus and damping in soil: measurement and parameter effects, J. Soil Mech. Found. Div. 98, 603-624.

Hardin, B. O., and V. P. Drnevich (1972b). Shear modulus and damping in soil: design equations and curves, J. Soil Mech. Found. Div. 98, 667-692.

Hartzell, S. H. (1992). Site response estimation from earthquake data, Bull. Seismol. Soc. Am. 82, no. 6 2308-2327.

Hartzell, S. H., L. F. Bonilla, and R. A. Williams (2004). Prediction of nonlinear soil effects, Bull. Seismol. Soc. Am. 94, no. 5, 1609-1629.

Hashash, Y. M. A., and D. Park (2001). Non-linear one-dimensional seismic ground motion propagation in the Mississippi embayment, Eng. Geol. 62, 185-206.

Hashash, Y. M. A., and D. Park (2002). Viscous damping formulation and high frequency motion propagation in non-linear site response analysis, Soil Dyn. Earthquake Eng. 22, 611-624.

Hayashi, H., M. Honda, and T. Yamada (1992). Modeling of nonlinear stress strain relations of sands for dynamic response analysis, in Proceedings of the World Conference on Earthquake Engineering, Madrid, Spain, Vol. 11, 6819-6825.

Houck, C. R., J. A. Joines, and M. G. Kay (1996). Comparison of genetic algorithms, random restart and two-opt switching for solving large location-allocation problems, Comput. Oper. Res. 23, 587-596.

Housner, G. W., and C. C. Thiel Jr. (1990). Competing against time: report of the Governor's Board of Inquiry on the 1989 Loma Prieta earthquake, Earthq. Spectra 6, no. 4, 681-711.

Iai, S., T. Morita, T. Kameoka, Y. Matsunaga, and K. Abiko (1995). Response of a dense sand deposit during 1993 Kushiro-Oki earthquake, Soils Found. 35, 115-131.
Idriss, I. M., and H. B. Seed (1968). Seismic response of horizontal soil layers, J. Soil Mech. Found. Div., 94, 1003-1031.

Idriss, I. M., and J. I. Sun (1992). SHAKE91: User's Manual, Center for Geotechnical Modeling, Department of Civil and Environmental Engineering, University of California, Davis, California.

Ishihara, K. (1996). Soil Behavior in Earthquake Geotechnics, Clarendon Press, Oxford, $350 \mathrm{pp}$.

Iwan, W. D. (1967). On a class of models for the yielding behavior of continuous and composite systems, J. Appl. Mech. 34, 612-617.

Japanese Geotechnical Society (1996). Soils and Foundations, Special Issue on Geotechnical Aspects of the January 17, 1995, Hyogoken-Nambu Earthquakes.

Joyner, W. B., T. E. Fumal, and G. Glassmoyer (1994). Empirical response spectral ratios for strong motion data from the 1989 Loma Prieta, California, earthquake, in Proceedings of the 1992 NCEER/SEAOC/ BSSC Workshop on Site Response During Earthquakes and Seismic Code Provisions, G. R. Martin (Editor), National Center for Earthquake Engineering Research, Buffalo, New York, Special Publication No. NCEER-94-SP01.

Joyner, W. B., R. E. Warrick, and A. A. Oliver III (1976). Analysis of seismograms from a downhole array in sediments near San Francisco Bay, Bull. Seismol. Soc. Am. 66, 937-958.

Konder, R. L., and J. S. Zelasko (1963). A hyperbolic stress-strain formulation for sands, in Proceedings of the 2nd Pan American Conference on Soil Mechanics and Foundation Engineering, Sao Paulo, Brazil, 289-324.

Kramer, S. L. (2006). Engineering and science needs for GSMA sites: an invited opinion paper, in Proceedings COSMOS 2nd Workshop for Site Selection, Installation and Operation of Geotechnical Strong-Motion Arrays: Guidelines for Installation, Operation, and Data Archiving and Dissemination, University of California, San Diego, San Diego, California, 17-19 May 2006.

Kwok, A. O., J. P. Stewart, Y. M. A. Hashash, N. Matasovic, R. Pyke, Z. Wang, and Z. Yang (2008). Use of exact solutions of wave propagation problems to guide implementation of nonlinear seismic ground response analysis procedures, J. Geotech. Geoenviron. Eng. 133, no. $11,1385-1398$.

Liu, P.-C., and R. J. Archuleta (2002). The effect of a low-velocity surface layer on simulated ground motion, Seism. Res. Lett. 73, 267.

Liu, P.-C., and R. J. Archuleta (2006). Efficient modeling of $Q$ for 3D numerical simulation of wave propagation, Bull. Seismol. Soc. Am. 96, no. 4A, 1352-1358.

Liu, P.-C., R. J. Archuleta, and S. H. Hartzell (2006). Prediction of broadband ground-motion time histories: hybrid low/high-frequency method with correlated random source parameters, Bull. Seismol. Soc. Am. 96, 2118-2130.

Ma, S., and P.-C. Liu (2006). Modeling of the perfectly matched layer absorbing boundaries and intrinsic attenuation in explicit finite-element methods, Bull. Seismol. Soc. Am. 96, no. 5, 1779-1794.

Masing, G. (1926). Eigenspannungen und verfertigung beim messing, in Proceedings of the 2 nd International Congress on Applied Mechanics, Zurich.

Matasovic, J., and M. Vucetic (1993). Analysis of seismic records obtained on November 24, 1987 at the Wildlife Liquefaction Array, Research Report, Civil Engineering Department, University of California, Los Angeles, $94 \mathrm{pp}$.

Matasovic, M., and M. Vucetic (1995). Generalized cyclic-degradationpore-pressure generation model for clays, J. Geotech. Eng. 121, no. $1,33-42$.

Mroz, Z. (1967). On the description of anisotropic workhardening, J. Mech. Phys. Solids 15, 163-175.

Ohsaki, Y. (1969). The effects of local soil conditions upon earthquake damage, in Proceedings Specialty Session on Soil Dynamics, 7th ICSMFE.

Oppenheim, A. V., and R. W. Schafer (1999). Discrete Signal Processing, Prentice Hall, New York.

Park, D. (2003). Estimation of Nonlinear Seismic Site Effects for Deep Deposits of Mississippi Embayment, Department of Civil and Environ- 
mental Engineering, University of Illinois at Urbana-Champaign, Urbana, $337 \mathrm{pp}$.

Park, D., and Y. M. A. Hashash (2004). Soil damping formulation in nonlinear time domain site response analysis, J. Earthq. Eng. 8, no. 2, 249-274.

Park, D., and Y. M. A. Hashash (2005). Evaluation of seismic site factors in the Mississippi embayment. II. probabilistic seismic hazard analysis with nonlinear site effects, Soil Dyn. Earthquake Eng. 25, 145-156.

Romero, S. M. (2001). Ground Motion Amplification of Soils in the Upper Mississippi Embayment, Department of Civil and Environmental Engineering, Georgia Institute of Technology, Atlanta.

Rosenblueth, E. (1960). Earthquake of 28 July 1957 in Mexico City, in Proceedings of the 2nd WCEE, Vol. 1, 359-379.

Satoh, T., M. Fushimi, and Y. Tatsumi (2001). Inversion of strain-dependent nonlinear characteristics of soils using weak and strong motions observed by boreholes sites in Japan, Bull. Seismol. Soc. Am. 91, $365-380$.

Satoh, T., and H. Kawase (1995). Nonlinear behavior of soil sediments identified by using borehole records observed at the Ashigar Valley, Japan, Bull. Seismol. Soc. Am. 85, no. 6, 1821-1834.

Sato, K., T. Kokusho, M. Matsumoto, and E. Yamada (1996). Nonlinear seismic response and soil property during strong motion, Soils and Foundations, Special Issue on Geotechnical Aspects of the January 17, 1995, Hyogoken-Nambu Earthquakes, 41-52.

Schnabel, P. B., J. Lysmer, and H. B. Seed (1972). SHAKE: a computer program for earthquake response analyses of horizontally layered sites, Earthquake Engineering Research Center (EERC) Report No. EERC 72-12, University of California, Berkeley.

Seed, H. B., and I. M. Idriss (1970a). Analyses of ground motions at Union Bay, Seattle during earthquakes and distant nuclear blasts, Bull. Seismol. Soc. Am. 60, 125-136.

Seed, H. B., and I. M. Idriss (1970b). Soil moduli and damping factors for dynamic response analyses, Earthquake Engineering Research Center (EERC) Report No. UCB/EERC-70/10, University of California, Berkeley.

Seed, H. B., and M. P. Romo (1987). Relationships between soil conditions and earthquake ground motions in Mexico City in the earthquake of September 19, 1985, Earthquake Engineering Research Center (EERC) Report No. EERC-87-15, University of California, Berkeley.

Seed, H. B., R. T. Wong, I. M. Idriss, and K. Tokimatsu (1984). Moduli and damping factors for dynamic analyses of cohesionless soils, Earthquake Engineering Research Center (EERC) Report No. UCB/ EERC-84, University of California, Berkeley.

Seed, H. B., R. V. Whitman, H. Dezfulian, R. Dobry, and I. M. Idriss (1972). Soil conditions and damage in the 1967 Caracas earthquake, J. Soil Mech. Found. 98, 787-806.

Silva, W. J. (1991). Global characteristics and site geometry, Chapter 6 in Proceedings of the NSF/EPRI Workshop on Dynamic Soil Properties and Site Characterization, Palo Alto, California, Electric Power Research Institute Report No. NP-7337.

Silva, W. J., and C. L. Stark (1992). Source, path, and site ground motion model for the 1989 M 6.9 Loma Prieta earthquake, Calif. Div. Mines Geol. Final Rept.

Steidl, J. H., A. G. Tumarkin, and R. J. Archuleta (1996). What is a reference site?, Bull. Seismol. Soc. Am. 86, 1733-1748.

Stoffa, P. L., and M. K. Sen (1991). Nonlinear multi-parameter inversion using genetic algorithms: inversion of plane-wave seismograms, Geophysics 56, 1794-1810.

Streeter, V. L., E. B. Wylie, and F. E. Richart Jr. (1974). Soil motion computations by characteristics method, J. Geotech. Eng. Div. 100, no. GT3 247-263.

Su, F., K. Aki, T. Teng, Y. Zeng, S. Koyanagi, and K. Mayeda (1992). The relation between site amplification factor and surficial geology in central California, Bull. Seismol. Soc. Am. 82, no. 2 580-602.

Tezcan, S. S., V. Yerlici, and H. T. Durgunoglou (1979). A reconnaissance report for the Romanian earthquake of 4 March 1977, Eng. Struct. Dyn. 6, 397-421.

Toro, G. R., and W. J. Silva (2001). Scenario earthquakes for Saint Louis, $\mathrm{MO}$, and Memphis, TN, and seismic hazard maps for the central United States region including the effect of site conditions, Risk Engineering, Inc., Boulder, Colorado, U.S. Geol. Surv. Grant: Final Tech. Rept.

Wen, K., I. Beresnev, and Y. T. Yeh (1994). Nonlinear soil amplification inferred from downhole strong seismic motion data, Geophys. Res. Lett. 21, 2625-2628.

Wiggins, J. H. (1964). Effects of site conditions on earthquake intensity, J. Struct. Div. 90, no. ST-2, 279-313.

Zeghal, M., and A. W. Elgamal (1994). Analysis of site liquefaction using earthquake records, J. Geotech. Eng. 120, no. 6, 996-1017.

Zhu, L., and L. Rivera (2001). Computation of dynamic and static displacement from a point source in multi-layered media, Geophys. J Int. 148, 619-627.

Georgia Institute of Technology

School of Civil and Environmental Engineering

Atlanta, Georgia 30332-0355

(D.A., W.L.)

Institute for Crustal Studies

1140 Girvetz Hall

University of California

Santa Barbara, California 93106-1140

(J.S., J.S.)

Manuscript received 24 August 2007 